\title{
Los Maestros de obras aprobados por la Real Academia de Bellas Artes de San Fernando (1816-1858). Una profesión en continuo conflicto con los arquitectos
}

\author{
Rosario Santamaría Almolda *
}

\begin{abstract}
RESUMEN
Los maestros de obras fueron unos profesionales titulados a los cuales la legislación les reconoció una serie de facultades para diseñar $y$ dirigir construcciones. Estas facultades provocaron a lo largo del siglo XIX un continuo conflicto de competencias profesionales con los arquitectos. Tenían los maestros de obras menos conocimientos $y$ estudios que los arquitectos por sus menos años de carrera, pero con suficiente capacidad científica para proyectar. Estos diplomados después de un período de formación en las Academias o en los estudios de los arquitectos $y$, posterioremente en la Escuela Especial de Arquitectura, sabian conjugar la teoría con la práctica.
\end{abstract}

\section{ABSTRACT}

The work managers were qualified professionals with less knowledges than the architects but with enought scientific capacity for making a proyect. The law admited that they were able to design and run a construction proyect and this will produce in the XIX century a clash of professional competences between architecs and works managers as this work managers after a period of studies in academies or in the office of the architecs, and after that in the Special School of Architecture, were able to put together theory and practique.

* Doctora en H. ${ }^{a}$ del Arte. U.N.E.D. 
Hasta que se fundó la Escuela Especial de Arquitectura por un real decreto de 25 de septiembre de $1844 \mathrm{y}$, desde que por una real orden de 1816 se volvió a restablecer la profesión de maestro de obras, abolida desde 1796, será la Real Academia de Bellas Artes de San Fernando la encargada de otorgar los títulos de esta disciplina académica —mediante los diferentes exámenes que evaluaban los conocimientos necesarios para ejercer esta profesión-, en todo el Reino y dominios de S.M., así como, las academias de San Carlos, San Luis y la Concepción, en sus respectivos distritos geográficos de Valencia, Zaragoza y Valladolid.

La supresión de este título por una real orden de septiembre de 1796, firmada en San Ildefonso por el Príncipe de la Paz D. Manuel de Godoy y Álvarez de Faria ${ }^{1}$, se encuadra en la crisis de la última década del siglo XVIII por la que pasó el Instituto madrileño y la reestructuración de las profesiones de la Arquitectura debido a la necèsidad de reformar los planes de estudios de estas disciplinas académicas.

Esta renovación de los estudios para adecuarlos a los cambios experimentados por la teoría y la práctica del arte de edificar, pusieron en duda que el arquitecto recibiera una formación tan completa como era necesaria para el ejercicio de su profesión. Y, paralela a esta opinión se pensaba, asimismo, que se examinaba de maestros de obras a individuos con limitadas facultades teóricas y sólo expertos en la práctica constructiva, por lo que se aconsejaba que en adelante la Academia examinase y otorgase los títulos a aquellos futuros profesionales que uniesen en su persona, no sólo la teoría sino también la práctica constructiva. De ahí, que se suprimiese la clase de maestros de obras.

Sin embargo, esta profesión, se volvió a institucionalizar y se otorgó, otra vez, este diploma académico. Uno de los datos que se deducen de esta restauración es que no fue la Academia de Bellas Artes de San Fernando la que tomó la iniciativa de este restablecimiento, sino que fueron las Academias de San Carlos de Valencia y de San Luis de Zaragoza las que presionaron para que se volvieran a conceder estos títulos, por supuesto, mediante la superación de los estudios necesarios y sus correspondientes prácticas edificatorias ${ }^{2}$.

1 Archivo Academia de Bellas Artes de San Fernando. Real Orden de 18 de Septiembre de 1796 Para que no examine la Academia de Maestros de obras con facultades limitadas.Leg.: 165/2. (Desde ahora A.A.S.F.)

2 Carta de D. Martín Fernández de Navarrete a D. Vicente María de Vergara comunicando estas novedades. La carta dice así: «Examinadas por la Real Academia de San Fernando las fundadas reclamaciones con que repetidamente han solicitado el restablecimiento de la clase de maestros de obras las Reales Academias de San Carlos de Valencia y de San Luis de Zaragoza, 
Los Maestros de obras aprobados por la Real Academia de Bellas Artes...

Esta restauración, sería a lo largo de casi todo el siglo XIX, un punto de fricción con los arquitectos por la dificultad de fijar y señalar las competencias de unos y de otros, ya que este profesional será también un titulado al que la legislación le reconocerá una serie de facultades para proyectar. La diferencia entre arquitectos y maestros de obras se distinguirá, únicamente, entre las obras públicas que tenían que estar dirigidas bajo el control de un arquitecto y, las de carácter privado y particular que las podrían dirigir los maestros de obras.

Desde que se volvió a restablecer el diploma de maestro de obras por la real orden de 28 de agosto de 1816, firmada en Palacio por Pedro Ceballos, hasta 1858, último año en que examina la Academia para otorgar el título de esta disciplina académica, se titularon en el Instituto madrileño 291 nuevos profesionales. Aunque, ya estaba en funcionamiento la Escuela Especial de Arquitectura,sin embargo, era la Academia de Bellas Artes de San Fernando la que otorgaba los títulos mediante la realización de un examen de reválida, hasta 1857 en que la Ley Moyano, la apartará definitivamente de esta labor examinadora ${ }^{3}$. Además, el primero de los nuevos titulados, fue Manuel Martínez Zoilo un maestro de obras que se le concedió el título el 12 de octubre de 1815, cuando todavía no estaba restaurada esta profesión y se le otorgó por real orden ${ }^{4}$.

Hay unos años desde que se funda la Escuela Especial de Arquitectura hasta cuando la Academia ya no otorgará diplomas, en que existen dos formas de conseguir los títulos de maestros de obras. Aquéllos que habían estudiado la carrera en la Escuela y que revalidan el título en la Real Academia de San Fernando, y, aquéllos otros que

se consultó al Rey lo que estimó conveniente, mandando en consecuencia S.M. que se restableciese dicha clase y se expidiesen sus títulos en personas en quienes concurriesen aquellas circunstancias y conocimientos que la Academia juzgase conveniente prescribir en la Ordenanza de Arquitectura en que se ocupaba, para que desde luego y entretanto que se concluia, aprobaba y daba a luz, se proveyese al público de los maestros de obras que exigía la necesidad de restaurar o levantar de nuevo tantos edificios particulares como quedaron arruinados en la pasada guerra...ha acordado la Academia de San Fernando remita a V.S. copia del capítulo tercero de la nueva ordenanza, en que trabaja por una comisión de profesores y comprende los ejercicios a que ahora deben sujetarse los profesores de esta arte que aspiren al grado de maestros de obras... Madrid, 11 de octubre de 1817". A.A.S.F. Leg.: $15-5 / 2$

3. Registro de maestros de obras aprobados por la Real Academia desde 1818 hasta 1886. Registro de los maestros de obras aprobados por la Real Academia de Nobles Artes de San Fernando, a resultas de la Real Orden de 28 de agosto de 1816 por la cual S.M. a consecuencia del plan propuesto por la Academia en Junta Ordinaria de 4 del mismo y que se acordó elevar al Rey N.S. para su aprobación por la Academia. A.A.S.F. Leg.: 3/156

4 Expediente de Manuel Martínez Zollo. A.A.S.F. Leg.: 15-4/2 
por pertenecer al plan de estudios anterior a la fundación del nuevo instituto y, después del plazo y prórroga concedidos para los que tenían comenzada la carrera en las escuelas establecidas por las Academias, los examinará una junta de profesores de la Sección de Arquitectura de San Fernando.

\section{ORDENANZA ARTISSTICA: NUEVA REGLAMENTACIÓN DE LAS PROFESIONES DE LA ARQUITECTURA}

Posteriormente a la real orden que sancionó la nueva reestructuración de la Arquitectura, la Real Academia madrileña publicó una ORDENANZA ARTÍSTICA ${ }^{5}$, que reglamentaba todas las profesiones del arte de edificar. Estaba dividida en seis capítulos y a su vez en diferentes artículos. El que concernía a los maestros de obras era el Capítulo Tercero, dividido a su vez, en trece artículos en los cuales se hacía saber los requisitos, exámenes y una vez obtenido el título, las facultades, derechos y exenciones. Este reglamento estuvo en vigor hasta que se firmó el siguiente en 1844.

Los aspirantes que no hubieran realizado los estudios necesarios para desempeñar esta profesión en las distintas Academias, tenían que demostrar dónde y que estudios hicieron y, asimismo, acreditar por lo menos dos años de práctica al lado de algún académico de mérito o de arquitecto. También debían presentar documento acreditativo de poseer buena conducta. Es de destacar, que la preparación necesaria para obtener el título de maestro de obras -igual que les sucedía a los arquitectos-, no era obligatorio realizarlos en las Academias, lo que sí tenían potestad única era la de evaluar, mediante exámenes, si los aspirantes estaban capacitados para desarrollar las diferentes disciplinas arquitectónicas y otorgar los títulos correspondientes.

Los estudios exigidos a estos profesionales comprendian una serie de asignaturas y materias que estaban relacionados con las facultades que tenían que desarrollar, si bien en el justo concepto de ser una titulación media. Es decir, una profesión con menos conocimientos y estudios que el arquitecto, pero con suficiente preparación científica para poder desarrollar edificios civiles e hidráulicos. Por tanto, un profesional, no un simple practicón,

\footnotetext{
5 La Ordenanza Artística reglamentaba las clases de graduaciones de la profesión de arquitectura, en cuatro Capítulos. El Capítulo Tercero expecificaba en 13 artículos todo lo concerniente a los maestros de obras. A.A.S.F. Leg.: 17-3/1.
} 
que, después de un período de formación en las Academias o en los estudios de los académicos o arquitectos, supiese conjugar la teoría con la práctica.

Para ser admitidos a examen los futuros maestros de obras tenían que presentar un edificio de su invención en planta, fachada y corte geométri$\mathrm{co}$, con su correspondiente informe práctico facultativo y presupuesto de la obra. Este era el primer paso que tenían que realizar estos futuros profesionales para alcanzar el título académico. Se llamaba a este ejercicio Prueba de Pensado. La única diferencia con el realizado por los arquitectos, era que la construcción presentada por aquellos futuros profesionales era un "edificio de segundo orden" o si era un hospital, teatro, biblioteca, cementerio, ayuntamiento, etc. eran proyectos, por lo general, de menor extensión que los realizados por los arquitectos.

Si el informe de este ejercicio presentado en la Secretaría de la Academia y examinado por la Comisión de Arquitectura era favorable, el pretendiente sería admitido a realizar el segundo examen llamado Prueba de Repente. Consistía el ejercicio en la elección de un tema de tres que salían al azar al meter tres veces la plegadera el vice-protector en el Libro de asuntos para Maestros de obras. Este libro se componía de 55 temas ${ }^{6}$, y el ejercicio consistía en desarrollar en el tiempo estipulado de 15 horas temas como:

«N. ${ }^{\circ} 1$. Casa fábrica de jabón con todas sus oficinas correspondientes. Planta, fachada y corte.

«N. ${ }^{\circ}$ 7. Una escuela de primeras letras y cátedra de latinidad para un pueblo de 500 vecinos con habitaciones para los maestros. Planta, fachada y corte.

«N. ${ }^{\circ} 28$. Disponer para un pueblo un hospital de caridad que contenga 24 camas, con habitación para el enfermero, cocina, dispensa y cuarto para el capellán, demostrándolo en planta, fachada y corte».

«N. ${ }^{\circ} 55$. Proyectar un odeón o pequeño templete elevado en una plaza - paseo público para la colocación de un cuerpo de música. Planta, fachada y corte.

Se llamaba a este examen Prueba de Repente porque, se tenía que realizar desde las siete de la mañana hasta las diez de la noche en las

6 Este libro comprende el temario de los 55 temas con el siguiente título: «Libro de asuntos para Maestros de Obras». A.A.S.F. Signatura 333/4. 


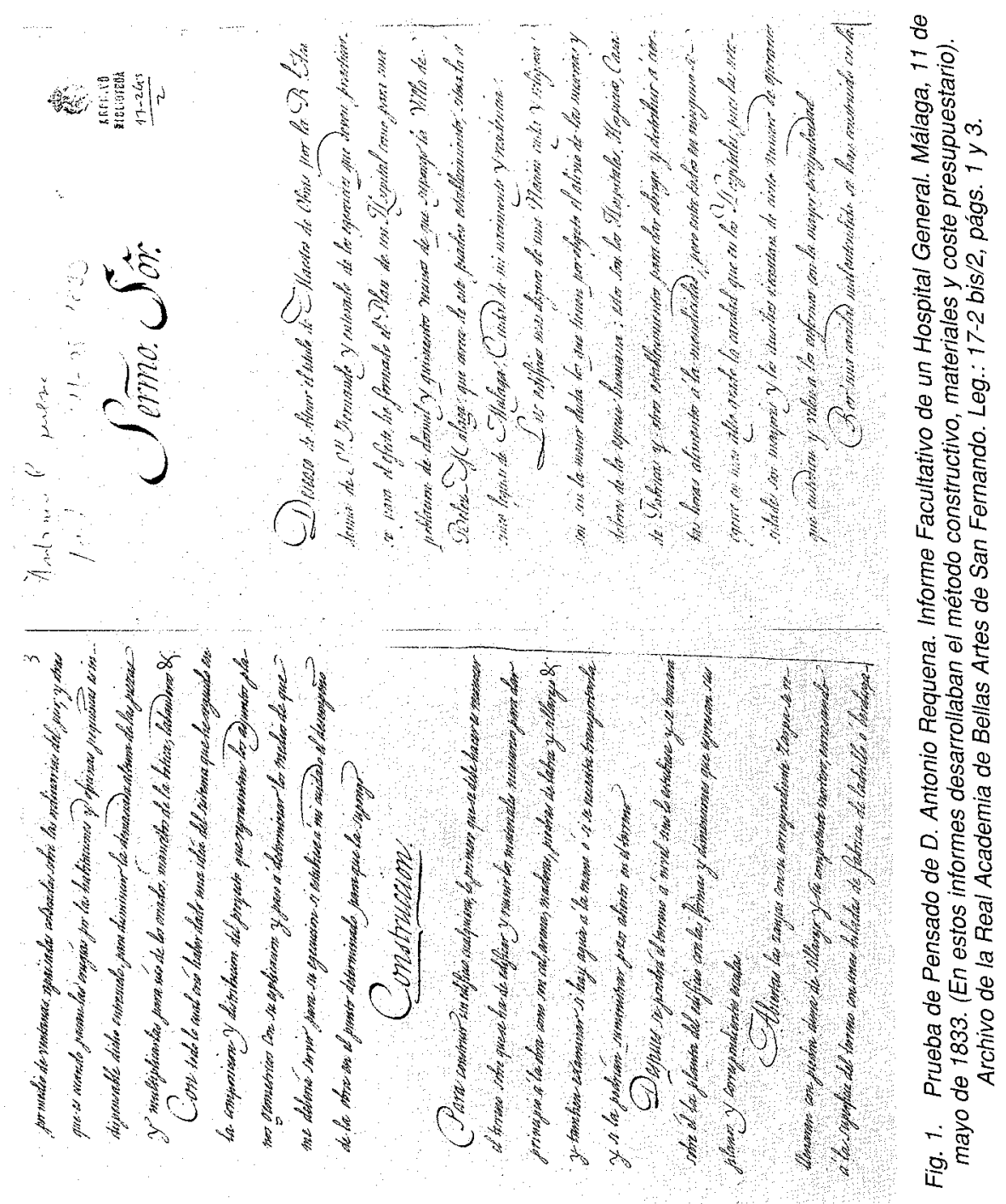




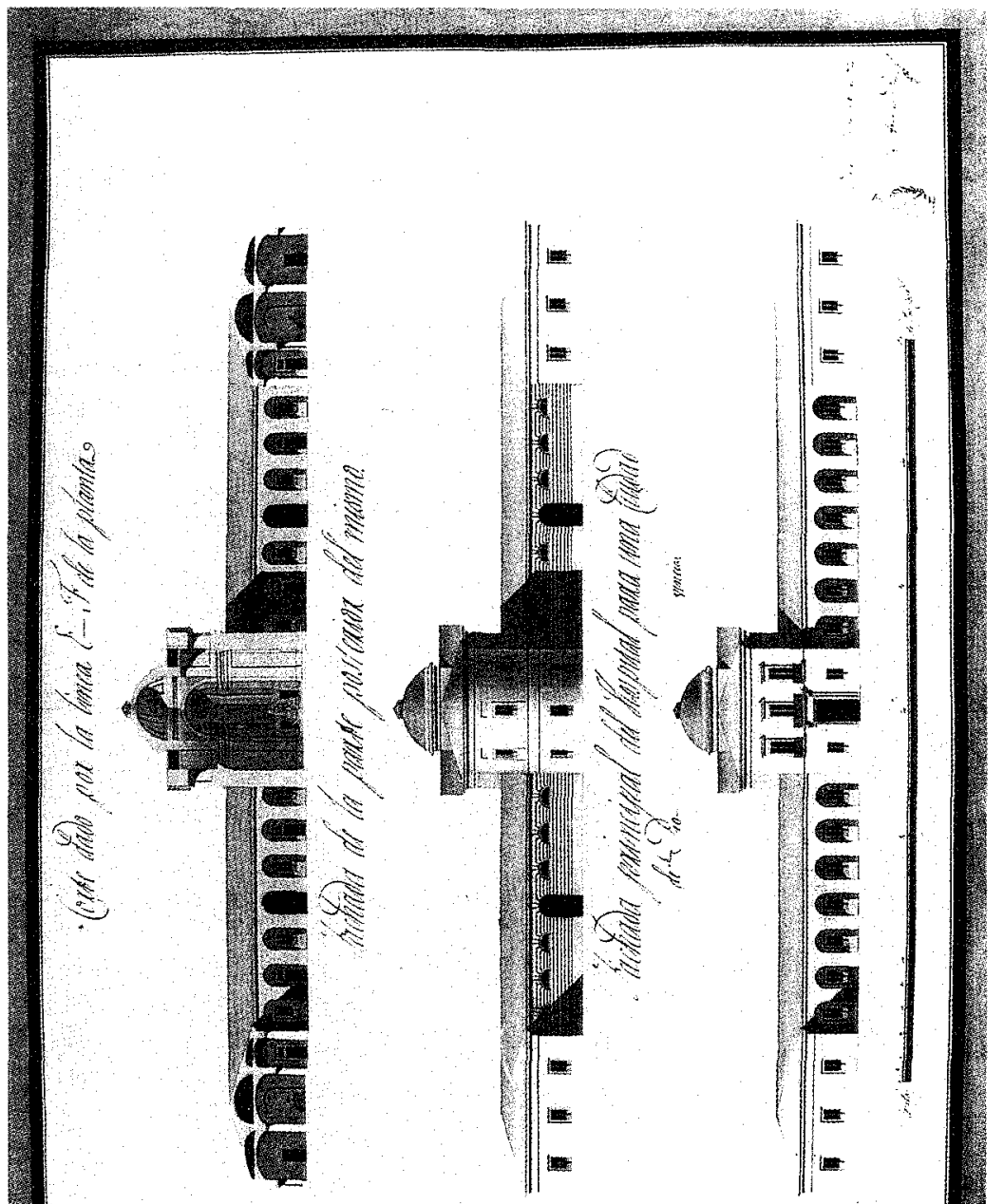

$\frac{\pi}{8} \frac{\pi}{\pi}$

ज

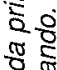

ช

के

世ㄴ

$\therefore$

$\infty$

$8 \%$

这

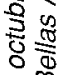

o

80

6

व.

홍

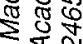

Ni⿱宀⿻三丨口

के प⿺

옹

ह

웡

厂

कू

(4

용

8

范

등

ब

$\frac{8}{0} 8$

路 돈

i 홍

ن 
aulas de la sede académica. Se les dejaba, asimismo, utilizar los libros clásicos de arquitectura que existían y poseía la Academia en su biblioteca ${ }^{7}$.

$Y$ un tercer ejercicio oral ante un tribunal examinador formado a tal efecto, sobre Aritmética, Geometría elemental y práctica y sobre todo cuanto tenía relación con los casos prácticos de la profesión como medida y tasación de edificios, obras hidraúlicas, comunes y particulares ${ }^{8} \mathrm{y}$, también, se le preguntaría sobre la prueba de pensado y de repente realizadas por el aspirante y su comparación entre ellas.

Una vez aprobado y conseguido el título todo maestro de obras estaría autorizado para «medir, reconocer, tasar, proyectar y dirigir toda clase de edificios comunes y particulares en lo civil e hidráulico en todos los dominios de esta Monarquía; pero se le prohibe el que verifique ninguna de estas operaciones en los edificios y obras públicas, santas iglesias, templos parroquiales o de comunidades religiosas a no ser en clase de segundo director» ${ }^{9}$. Como se puede comprobar por este artículo de la Ordenanza Artística, la única diferencia con los arquitectos es que los edificios a realizar por unos y por otros, se deslindaban únicamente en que fuesen comunes y particulares o públicos. Y si estas construcciones eran públicas, únicamente, en calidad de segundo director. Pero aún se amplían más las facultades de estos profesionales al reconocer que debido a la escasez de arquitectos en algunas ciudades y villas, quedaban también habilitados estos profesionales para ejercer en estos destinos, aunque sus facultades solamente serían extensivas "a las obras públicas del distrito o jurisdicción que comprenda su partido" ${ }^{10}$, aunque necesitaban para las obras de nueva planta y de consideración el visto bueno del «Maestro Mayor de la capital o Intendencia». Es de comprender con estas amplias faciltades, el continuo conflicto con los arquitectos a lo largo de casi todo el siglo XIX, hasta que un Decreto de $1871^{11}$ declaró libre esta profesión de maestro de obras y sus enseñanzas quedaron a cargo de las corporaciones populares, suprimiéndose esta profesión como enseñanza oficial.

\footnotetext{
Ordenanza Artística. Capítulo Tercero. Artículo $7 .^{\circ}$ Op. cit.

Ibídem. Artículo 8. .

Ibídem. Artículo 10..

lbídem. Artículo 12.

Martínez AlcubillaA, M.: Diccionario de la Administración Españaola, 6. ${ }^{2}$. edición, pág. 15 y 16. El decreto está firmado en Palacio por Amadeo de Saboya y por el ministro de Fomento Manuel Ruiz Zorrilla, a cinco de mayo de mil ochocientos setenta y uno.
} 


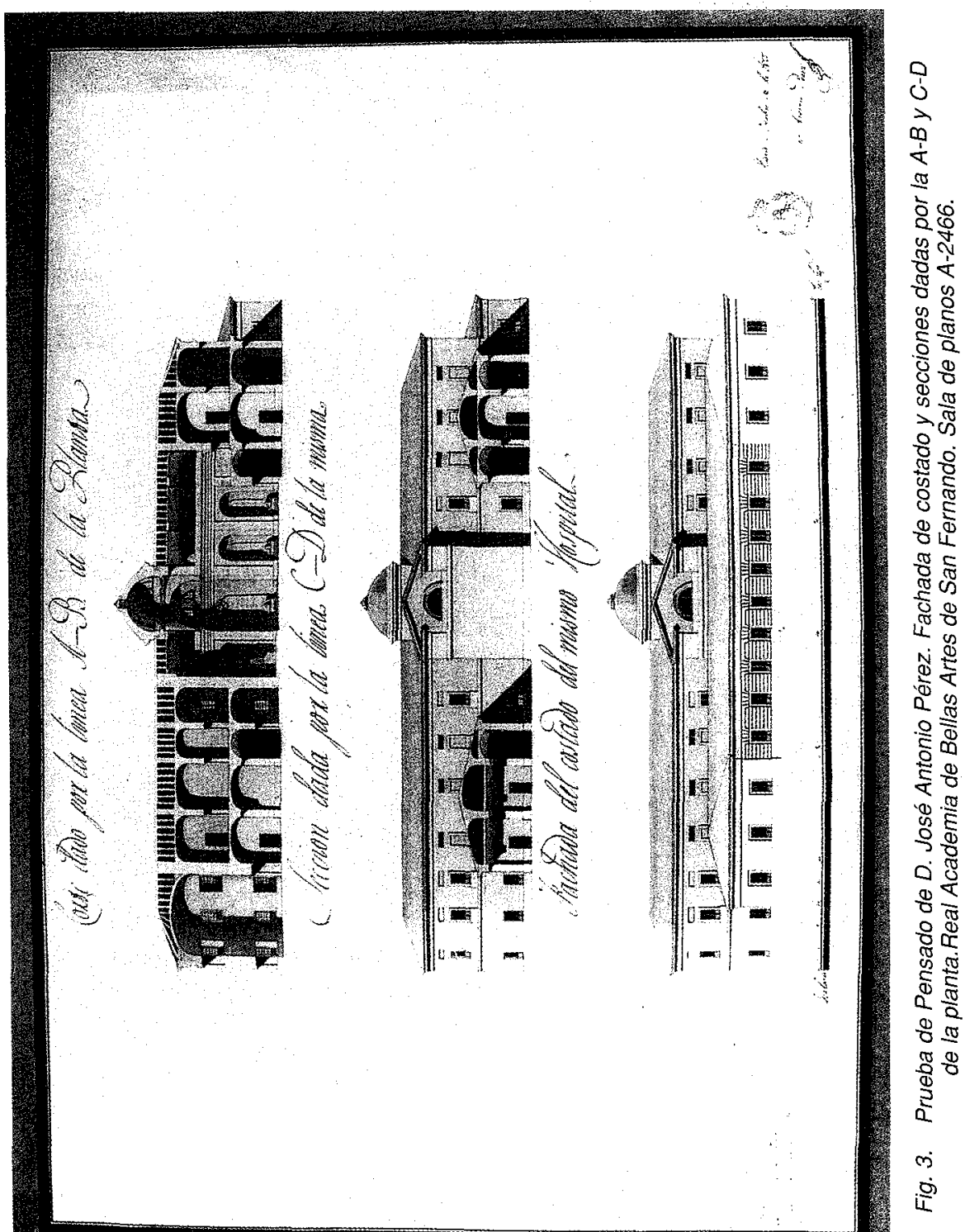




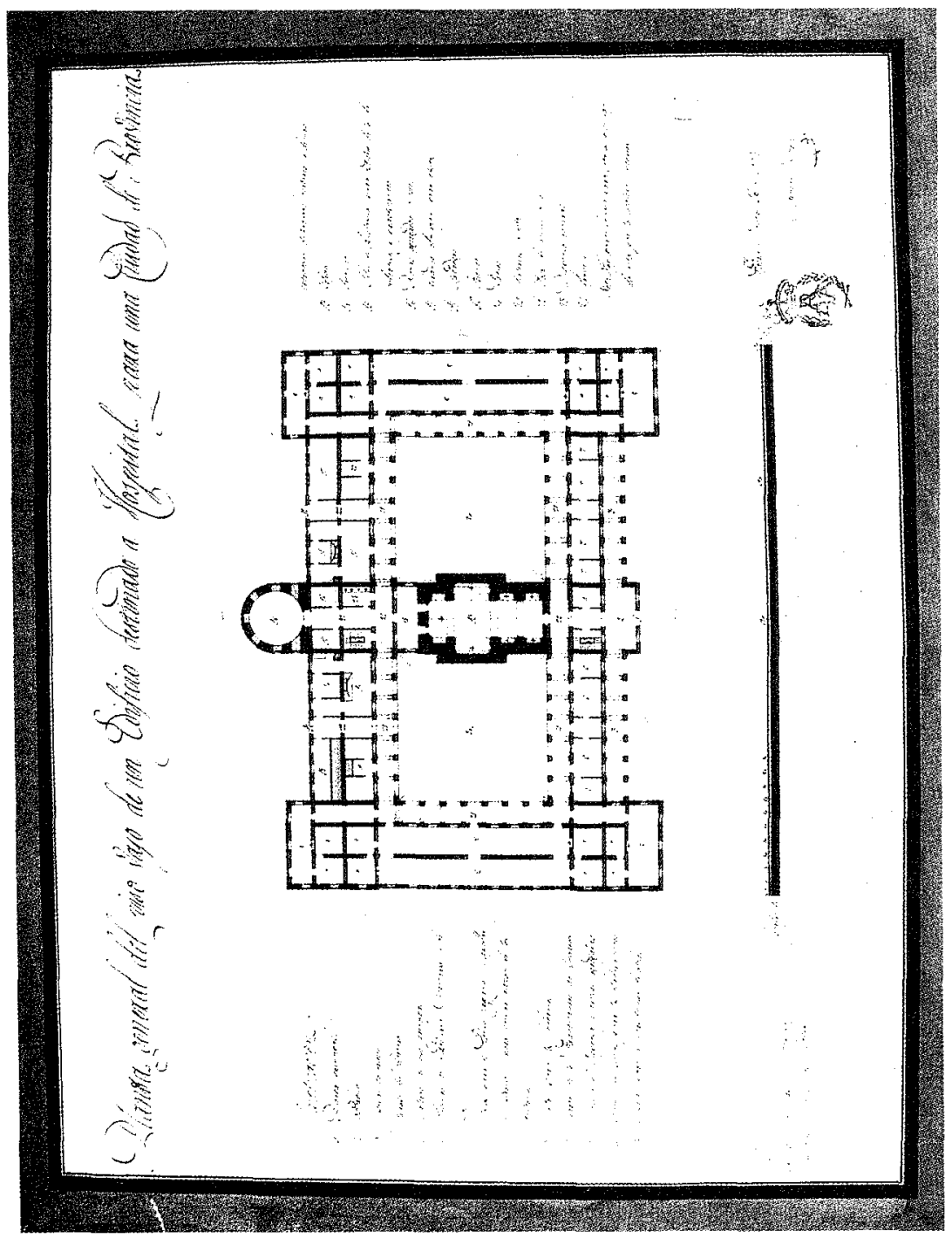




\section{FUNDACIÓN DE LA ESCUELA ESPECIAL DE ARQUITECTURA}

La Escuela Especial de Arquitectura ${ }^{12}$ fue fundada por un real decreto de 25 de septiembre de 1844. La creación de este nuevo centro oficial se encuadra dentro de la mejora de los planes de estudios y, desde su pretendjda adecuación a los cambios habidos en la enseñanza y práctica de la Arquitectura. Dichos cambios, aunque, dentro de una serie de intereses amplios, se promovieron desde la Academia. Desde esta coherencia, se consideró necesario la centralización de los estudios y, se obligó a los alumnos a la asistencia a las clases impartidas por los profesores de la nueva Escuela; así como, a la desaparición del examen libre y a su correspondiente preparación en los gabinetes de los académicos y arquitectos.

En tal contexto fueron reformados los programas de las carreras de Arquitectura. Por consiguiente, también, se reformaron los estudios y se regularizaron las facultades de los maestros de obras, y se creó una enseñanza especial para estos facultativos subalternos agregada a la nueva Escuela, señalándose de un modo bastante claro sus derechos y facultades en la real orden de 28 de septiembre de 1845.

Realmente estas reglamentaciones de 1845 se presentan como la primera disposición reguladora de las facultades de los maestros de obras en concurrencia con los arquitectos, ya que se les autorizó para construir toda clase de edificios bajo los planos y dirección de arquitecto y sin la necesidad de este facultativo en los pueblos menores de 2.000 vecinos y en los demás si no existiese aquel profesor ${ }^{13}$.

También se reglamentó en este año la enseñanza de estos profesionales diviendo los estudios en preparatorios y especiales ${ }^{14}$, siendo los primeros necesarios para la prosecución de los cursos de carrera.

12 Hernando, J.: Arquitectura en España (1770-1900), Madrid, Cátedra, 1989. «La Escuela de Arquitectura y la renovación pedagógica», págs. 168-171. NAvASCUÉS PALACIO, P.: «Arquitectura española (1808-1914). Summa Artis. Historia General del Arte. Vol. XXXV. Espasa Calpe, 1993». 4. De la Academia de Bellas Artes a la Escuela de Arquitectura, págs. 45-64.

13 Martínez Alcubilla, M.: Dic. op. cit. Real orden de 28 de septiembre de 1845, pág. 667.

14 Existe un cuadro comparativo de las enseñanzas de los arquitectos y maestros de obras que comprende las materias de ambas carreras y con las fechas y planes de estudios divididos en «Preparatorios» y «Especiales». Los correspondientes a los maestros de obras son los siguientes: Reglamento de 28 de septiembre de 1845. Preparatorios: Dibujo natural hasta cabezas, aritmética, álgebra, geometría elemental y práctica, idea de la naturaleza de las curvas y trazado de las principales. Especiales, 1. er año: Principios de geometría, Descriptiva y sus aplicaciones a las teorías y cortes de madera y, estudio de la montea; $2 .^{\circ}$ año: Principios de mecánica práctica, construcción y composición. En ambos años, además, delineación, lavado y copia de arquitectura. Real Decreto de 31 de octubre de 1849. Preparatorios: Instrucción primaria elemental completa. Geografía, $1 .^{\circ}$ y $2 .^{\circ}$ año de matemáticas elementales. Dibujo lineal o de figura. De carrera, $1 .{ }^{\text {er año: }}$ 
Un nuevo decreto de 31 de octubre de 1849 organizó con más extensión los estudios de estos profesionales, tanto preparatorios como los especiales o de carrera ${ }^{15}$. Éstos últimos durarian tres años y tendrían que realizarlos por obligación dentro de la Escuela Especial de Arquitectura, o, en las Academias de provincias autorizadas para ello, expidiéndose una vez concluida la carrera el título profesional por el Ministerio de Instrucción Pública.

Una nueva modificación tendría lugar el 16 de julio de $1852{ }^{16}$ en cuya fecha se dictó el último plan de enseñanza de estos profesionales, que viene a ser una repetición de los anteriores y, se estableció el nuevo reglamento conjunto para los estudios que habrían de cursar para las enseñanzas de maestros de obras, directores de caminos vecinales y agrimensores ${ }^{17}$. La duración de cada año lectivo comprendería desde el 15 de septiembre al 15 de mayo, reservando los últimos días de septiembre para los exámenes de ingreso y los primeros días del mes de mayo para los de fin de curso ${ }^{18}$. Para ingresar en estas enseñanzas, era necesario que los aspirantes se presentaran en la Secretaría de la Escuela Especial de Madrid, o en las Academias de las respectivas provincias, acompañados de sus padres o tutores, con un memorial que expresase sus nombres, apellidos, edad, etc, así como la partida de bautísmo legalizada y

Principios de geometría descriptiva con sus aplicaciones a la teoría de las sombras y cortes de carpintería y cantería. Práctica de toda clase de operaciones topográficas; $2 .^{\circ}$ año: Principios de mecánica teórica e industrial. Principios de construcción, conocimiento y análisis de los materiales; $3^{\text {er. }}$ año: Composición y ejecución de planos de edificios de tercer orden. Trazado y construcción de caminos y de las obras que les corresponden. Durante los tres años dibujo topográfico y de arquitecturas. Reglamento de 16 de junio de 1852. Preparatorios: Instrucción primaria completa. $1 .{ }^{\circ}$ y $2 .^{\circ}$ año de matemáticas elementales y dibujo lineal. Especiales o de carrera, 1er. año: Elementos de geometría descriptiva pura y su aplicación a las sombras, cortes de piedra y maderas. Topografía. Agrimensura. Dibujo topográfico a pluma y práctica de la topografía y manejo de los instrumentos; $2 .^{\circ}$ año: Nociones de mecánica como base fundamental e la construcción. Dibujo topográfico a color y delineación de arquitectura. $33^{\text {er }}$ año: Composición de edificios rurales y de tercer orden. Parte legislativa y práctica de la profesión. Ejercicios de composición. Está firmado este documento en Madrid, a 23 de mayo de 1872, por el entonces secretario de la Sección de Arquitrectrua D. FRANCISCO DE CUBAS. A.A.S.F. Leg.: 23-3/2.

15 Ibídem. Se puede observar en el Real Decreto de 31 de Octubre de 1849, cómo aumenta un año los cursos especiales o de carrera y también cambian las materias de los estudios preparatorios.

16 Ibídem.

17 La nueva normativa dice así: "Reglamento para las enseñanzas de Maestros de Obras, Directores de Caminos Vecinales y Agrimensores, que han de plantearse en la Escuela Especial de Arquitectura, y para las establecidas en las Academias provinciales de Bellas Artes de primera clase". Se compone de los siguientes apartados: Capítulo Primero: De las diferentes clases de enseñanza. Capítulo Segundo: De los Profesores. Capítulo Tercero: De los alumnos y Capítulo Cuarto: De los exámenes. Se desarrollan estos capítulos a su vez en 41 artículos. Está firmado en San Ildefonso, el 16 de julio de 1852.A.A.S.F. Leg.: 23-4/2.

${ }_{18}$ Ibídem. Capítulo Tercero. Artículo $15 .^{\circ}$. 
los documentos que acreditasen los estudios preparatorios que eran obligatorios y que estaban establecidos en los reales decretos ${ }^{19}$. Sin los cuales, no serían admitidos para empezar a cursar estas enseñanzas. Para ingresar en estos estudios se les exigía que por lo menos tuviesen cumplidos los diez y ocho años de edad ${ }^{20}$.

Punto importante también de esta última modificación, fueron los continuos exámenes a que estuvieron sometidos los alumnos a lo largo del curso para aprobar la suficiencia necesaria y el aprovechamiento de las enseñanzas. Se hacían evaluaciones de mitad y de final de curso, así como, de fin de carrera. Las notas para calificar el aprovechamiento y aptitud de los alumnos eran: sobresaliente, bueno, mediano y malo ${ }^{21}$. Una vez superados los tres años de estudios, podrían aspirar al título desde el $1 .{ }^{\circ}$ de octubre del año siguiente, previo conocimiento y aprobación del director, la solicitud al secretario de la Academia respectiva, acompañada de las certificaciones correspondientes y carta de pago de los derechos del título, así como, de las correspondientes prácticas constructivas ${ }^{22}$.

Una vez expedido el título los maestros de obras se hallaban autorizados para medir, reconocer, tasar, proyectar y dirigir, toda clase de edificios comunes y particulares, aunque se les prohibía realizar estas operaciones en los edificios públicos, templos parroquiales, comunidades religiosas, etc, a no ser en calidad de segundo director ${ }^{23}$, sin embargo, debido a la escasez de arquitectos, estos profesionales podrían ejercer en las ciudades y villas que no tengan arquitecto pero "con la precisa condición de que a sus nombramientos precederá siempre el informe y conocimiento de la Real Academia” ${ }^{24}$. Con estas amplias facultades y con las que les concedió el reglamento de 1845 , no es de extrañar los numerosos conflictos entre los maestros de obras y los arquitectos.

\section{UN CONFLICTO ENTRE TITULADOS: MAESTROS DE OBRAS $Y$ ARQUITECTOS}

El restablecimiento de la profesión de maestro de obras será durante gran parte del siglo XIX, un continuo punto de fricción con los arquitectos

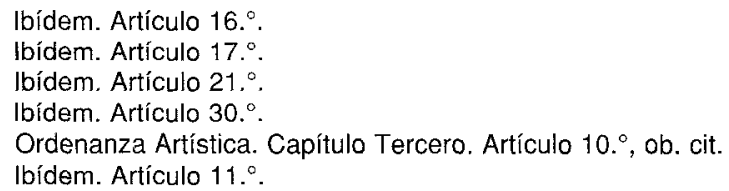


por la dificultad de fijar y deslindar las competencias de unos y de otros. EI útlimo reglamento que aprobó la reina Isabel II el 16 de julio de 1852, para las competencias de esta clase de profesional, intentó solucinarlo, pues, dejaba muy claro que eran éstos los auxiliares de los arquitectos, los ejecutores de sus órdenes. Pero este reglamento dejó, nuevamente, un resquicio y, era que en los pueblos que no llegasen a dos mil vecinos y en los demás que no hubiese arquitecto, los maestros de obras podrían suplir la falta de éstos. Con lo cual, se volvió a crear, otra vez, los mismos problemas que se intentaban solucionar.Todo ello, dió lugar a las continuas reclamaciones de los arquitectos y de la Real Academia de Bellas Artes de San Fernando, que terminó por abolirse nuevamente el título de maestro de obras el 24 de enero de 1855. Pero, debido a la presión de estos profesionales, así como a la falta de arquitectos, unido todo ello a la necesidad de edificaciones en poblaciones pequeñas, se volvió a restablecer por la Ley de Instrucción Pública de 1857, la denominada Ley Moyano. Los nuevos conflictos que surgieron, se intentaron solucionar con nuevos decretos. Entre ellos, el real decreto de 22 de julio de 1864, que señalaba y distinguía las atribuciones de los arquitectos, maestros de obras y aparejadores. Este reglamento provocó una agria protesta de los maestros de obras que incluso llegó al Congreso de los Diputados, que dió lugar a un segundo real decreto rublicado en San Ildefonso el 31 de agosto de 1865; estaba firmado por S.M. la reina Isabel II y por su ministro de la gobernación José Posada Herrera, el cual, salvaguardaba todos los derechos de los maestros de obras obtenidos por la legislación vigente cuando obtuvieron sus títulos. Y es que el real decreto de 22 de julio de 1864 introducía nuevos elementos de confusión, no solamente con los arquitectos, incluso también, con los mismos maestros de obras. Se permitía a los que estaban en posesión del título antes del reglamento de 1845, proyectar todo tipo de edificios particulares, mientras que los nuevos sólo lo podían hacer en poblaciones menores de 2.000 habitantes. Entre los propios maestros de obras se originó, incluso, cierta conflictividad competencial, simplemente, según la fecha en que hubiersen obtenido la titulación. De ahí, el posterior de julio de $1865^{25}$, que ampliaba la posibilidad de proyectar todo tipo de edificios particulares a los maestros de obras titulados antes de 1864.

Las anteriormente reseñadas órdenes, tampoco, resolvieron los problemas competenciales de los profesionales arquitectos y maestros de obras.

25 Martínez Alcubilla, M.: Diccionario..,op. cit. Real Orden de 31 de julio de 1865. tomo I, pág. 672. 
Las atribuciones de unos y de otros se diferenciaban, únicamente, en que los arquitectos eran los únicos que podían proyectar y construir edificios monumentales. Salvo eso, parece que en todo lo demás ambas carreras eran idénticas en el ejercicio de la profesión, estando, sin embargo, distantes en las condiciones que se les exigían para obtener sus respectivos títulos. Mientras el arquitecto tenía que estudiar, sobre todo a partir de la Escuela Especial de Arquitectura, un amplio Preparatorio y después de la Ley Moyano de 1857, ser bachiller; además, de cuatro, cinco o seis años de carrera, según los diferentes planes de estudios. A los maestros de obras y también dependientes de la Escuela, se les exigía un Preparatorio y dos o tres años de carrera, según sus respectivos planes, con bastantes menos asignaturas en ambas fases.

A esta continua confusión sobre las atribuciones profesionales, después del derrocamiento de la reina Isabel II y durante la regencia del general Serrano, un real decreto de 8 de enero de 1870 pondrá fin, al derogar todas las disposiciones dictadas anteriormente y permitirá a todos los maestros de obras, sin distinción de nuevos y antiguos, el poder proyectar y ejercer libremente su profesión en las construcciones particulares. Asimismo, también, como segundos directores o auxiliares de los arquitectos, en todos aquellos edificios que tengan carácter público, aunque sean de propiedad particular ${ }^{26}$.

Esta nueva reglamentación hará que estos titulados conserven durante el resto del siglo XIX y primeros años del XX, la posiblidad legal de proyectar edificios particulares, a pesar de que la ley de presupuestos de 1869 a 1870 suprimió la enseñanza oficial de maestro de obras, disolviendo las escuelas oficiales de Barcelona, Sevilla, Cádiz, Valencia, Valladolid y Madrid. La profesión de maestro de obras se declaró libre ${ }^{27}$, y, sus enseñanzas quedaron a cargo de las corporaciones populares y fuera de la esfera oficial que antes

26 GACETA de 21 de enero de 1870. Real decreto de 8 de enero de 1870. Los artículos $2 .^{\circ}$ y 3. Señalaban: «Los maestros de obras, sin la distinción de antiguos y modernos, cualquiera que sea la fecha en que hayan adquirido el título y su procedencia, podrán ejercer en todas partes libremente su profesión, quedando autorizados para proyectar, dirigir, tasar y reparar las casas y construcciones de propiedad particular". "Los maestros de obras quedan inhibidos de intervenir, como no sea en clase de segundos o auxiliares de los arquitectos, en los proyectos y construcción de toda obra o edificio que, ya por la procedencia de los fondos de que se costee, ya por el uso a que se destine, aún cuando sea de propiedad particular, como, por ejemplo, el culto, instrucción, beneficencia, espectáculos públicos u otro uso objeto análogo, tenga carácter de público". De todas las formas, en el artículo $6 .^{\circ}$, se permitía un cierto control de los arquitectos sobre las construcciones particulares proyectadas por los maestros de obras, ya que facultaba a los ayuntamientos para poder asesorarse de un arquitecto sobre las condiciones de solidez de estas edificaciones.

27 La libertad de la profesión de maestro de obras, no significó la posibilidad de proyectar obras particulares, facultad que quedó reservada a los titulados, tanto arquitectos como maestros de obras. Lo que se intentó al declarar libre la profesión fue acabar con una clase que escasamente se distinguía de los arquitectos. 
tenía. Eso sí, salvaguardando las garantías y privilegios de todos aquellos que obtuvieron el título oficial anteriormente. El nuevo decreto que sancionaba esta supresión, está firmado en Palacio a cinco de mayo de mil ochocientos setenta y uno, por Amadeo de Saboya y por su ministro de Fomento, Manuel Ruiz Zorrilla ${ }^{28}$. Estas nuevas normas, concedían, además, la posibilidad durante un año de obtener el título de maestro de obras a todos aquellos que al suprimirse las escuelas oficiales estuvieran matriculados en alguna de las asignaturas de la carrera, tuvieran aprobados cursos o estuvieran en el examen de reválida.

Aunque los maestros de obras titulados conservarán sus facultades de proyectar obras particulares, la supresión de los estudios de esta titulación, permitió la afirmación definitiva del arquitecto como único individuo que, en atención a su superior formación artística, tendrá la facultad de proyectar todo tipo de edificaciones. La consolidación de la profesión se acentuó cuando el real decreto de 20 de agosto de 1895 creó los estudios de aparejador. El nuevo profesional se perfiló como ayudante o auxiliar del arquitecto, aunque con funciones propias.

\section{APORTACIÓN DE LOS MAESTROS DE OBRAS A LAS DIFERENTES TIPOLOGIAS DECIMÓNICAS ARQUITECTÓNICAS}

Las Academias y después las Escuelas Especiales al asumir directamente el control de las enseñanzas y de las titulaciones relacionadas con la Arquitectura, abrieron definitivamente un abismo entre el profesional de la construcción y el artesano. Pero sobre todo, es en la profesión de maestro de obras donde se producirá el cambio más sustancial entre ambos. Ya que, aquel maestro de obras que años atrás procedía de la organización gremial, pasará a ser considerado como un titulado al poseer una sólida formación y estudios. Este nuevo maestro de obras, con el que el arquitecto mantendrá durante el sigio XIX una pugna por el ejercicio de sus respectivas competencias, será un diplomado con facultades para proyectar y con aptitud científica conferida por el Estado por estar respaldado por un título académico legal.

\footnotetext{
28 EI DECRETO dice así: «Conformándose con lo propuesto por mi Ministro de Fomento. Vengo en decretar lo siguiente: Artículo $1 .{ }^{\circ}$ Se declara libre el ejercicio de la profesión de Maestro de Obras y Aparejador. $2 .^{\circ}$. Se reserva su derecho a los que actualmente poseen título oficial de esta carrera a ocupar los destinos retribuidos de fondos generales, provinciales o municipales correspondientes a su clase, declarar en juicio y proyectar y dirigir con arreglo a las prescripciones actualmente vigentes". Dado en Palacio a cinco de mayo de mil ochocientos setenta y uno. -Amadeo._- El ministro de Fomento Manuell Ruiz Zorrilla. A.A.S.F. Leg.: 23-3/2.
} 
Los proyectos presentados por estos futuros profesionales para conseguir sus títulos, son reveladores, asimismo, de las necesidades constructivas del siglo XIX: iglesias parroquiales, casas consistoriales, posadasfondas, cementerios, hospitales, casas de beneficencia, colegios, molinos, aduanas, cárceles, alhóndigas y depósitos de grano, fábricas de jabón o de licores, hornos, casas de recreo, mercados, etc. es decir, construcciones relacionadas con las necesidades propias de los pueblos o municipios agrícolas o ganaderos, donde desarrollaban, generalmente, sus actividades los maestros de obras.

Estas memorias facultativas y sus correspondientes planos, tienen un valor documental inestimable a la hora de analizar las necesidades e ideales arquitectónicos de este importante período del siglo XIX, comprendido entre el neoclasicismo academicista y el romanticismo que intenta abrirse camino imponiendo aires de libertad.

Se ha hecho un seguimiento de los 292 maestros de obras que fueron aprobados por la Real Academia de Bellas Artes de San Fernando. De éstos, de 244 se ha podido averiguar el edificio que realizaron. Se han contabilizado las tipologías más proyectadas y se ha confeccionado un gráfico con el análisis comparativo de las diferentes pruebas de pensado. (Gráfico n. ${ }^{\circ} .1$ ).

\section{ANÁLISIS COMPARATIVO DE DIFERENTES PRUEBAS DE PENSADO}

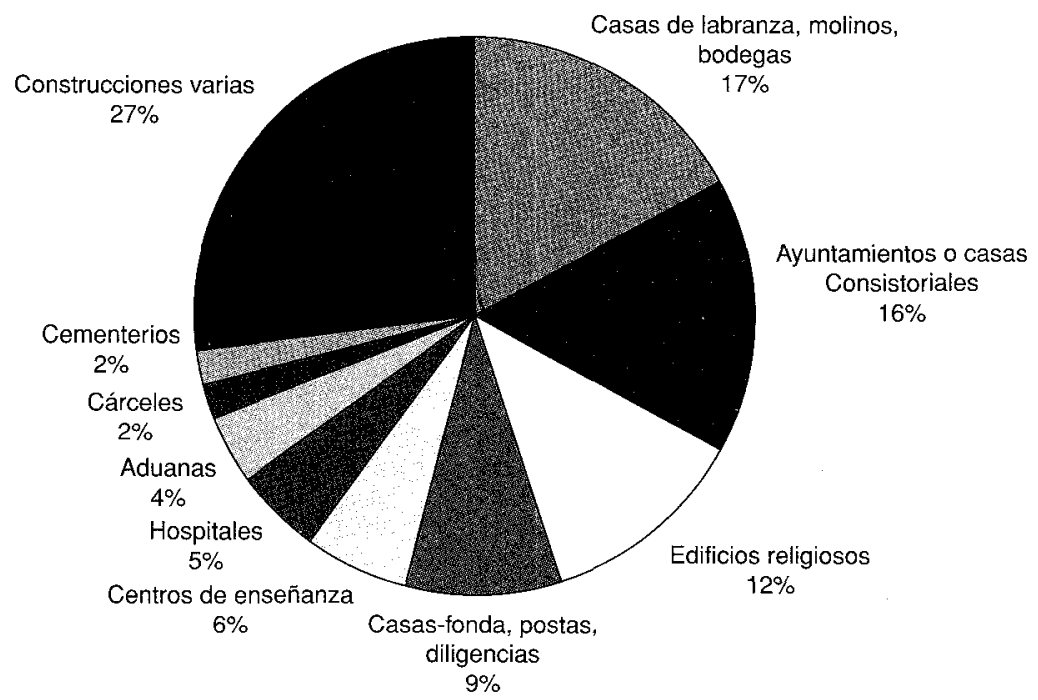

Gráfico 1. Análisis comparativo de las diferentes tipologías arquitectónicas. 
Casas de labranza, molinos, bodegas, etc. $\quad 41$

Ayuntamientos o casas consistoriales $\quad 40$

Edificios religiosos. 30

Casas-fonda, postas, diligencias 22

Centros de enseñanzas 15

Hospitales 11

Aduanas 10

Cárceles 5

Cementerios 4

Construcciones varias $\quad 66$

Totales 244

Uno de los datos que se deducen del estudio de los expedientes de estos diplomados es que consiguían su titulación relativamente mayores. El 60\% de estos profesionales tenían más de 30 años, siendo bastante normal los que acceden con más de 40 . Como se puede deducir de estos datos, no era lo normal acceder a esta profesión dedicándose a estos estudios desde jóvenes, si no después de ser un práctico en la arquitectura y, preparándose, después del trabajo con la asistencia a las clases nocturnas. En las cuales, conseguirían los conocimientos teóricos necesarios para realizar el correspondiente examen en las Academias. De esta forma accedían a esta titulación media. Hay que tener en cuenta, además, que no se podía optar al examen de maestro de obras -igual que les sucedía a los arquitectos-, si no tenían los 25 años cumplidos. A partir de 1850 se permitió a los maestros de obras acceder al título a los veintidos años «sin perjuicio de que después se conserve o se modifique la de veinte años que se señala como suficiente, y que a esta Corporación le parece algo escasa" ${ }^{29}$. Y efectivamente obtienen el título diez maestros de obras que tienen menos de 25 años: Agustín de Santa Cruz (24 años) ${ }^{30}$, Manuel García Sierra y Navarro (21años) ${ }^{31}$, José María Goyanes y Soldevilla (22 años) ${ }^{32}$, Gregorio de las Pozas (24 años) ${ }^{33}$, Pedro del Villar y Villarino (24

29 Junta de la Sección de Arquitectura de 16 de mayo de 1850. En dicha Junta se hace saber que el Sr. Ministro de Comercio Instrucción y Obras Públicas, recuerda a la Academia lo que está vigente respecto a las carreras de Jurisprudencia, Medicina y Farmacia y que suplica a la Corporación que se rebaje la edad a veinte y dos años para obtener el título de maestro de obras. Contestación de la Academia de fecha 12 de junio de 1850, aceptado el real decreto de 31 de octubre de 1849. A.A.S.F. Leg.: 19-3/2

30 Expediente de Agustín de Santa Cruz. A.A.S.F. Leg.: 19-4/2.

31 Ibídem. Expediente de Manuel García Sierra y Navarro.

32 Ibidem. Expediente de José María Goyanes y SOldevilla.

33 Ibídem. Expediente de Gregorio DE LAS POZAS. 
años) ${ }^{34}$, Indalecio Alzaá Yturralde (24 años) ${ }^{35}$, Eduardo Martínez García (21 años) ${ }^{36}$, Serafín Vergara y Villanueva (21 años) ${ }^{37}$, Ramón Losada Pérez (24 años) ${ }^{38}$ y Juan antonio Antúnez y García (22 años) ${ }^{39}$.

Otro de los datos que llama la atención en el estudio de estos profesionales, es la gran cantidad de ellos que son del País Vasco, concretamente 46 que corresponde a un $16 \%$ de toda esta profesión que se titula en este período. Le sigue Cataluña con 40 . También es muy importante la aportación de la región andaluza concretamente 65 . Del reino de Valencia a pesar de la importancia de la Academia de San Carlos 13, la gran mayoría son de Alicante. De la provincia de Valladolid 4 y de Zaragoza 12. Estos últimos, a pesar de tener sus respectivas Academias, prefirieron obtener el título por la de San Fernando.

\section{LOS MAESTROS DE OBRAS APROBADOS POR LA ACADEMIA DE BELLAS ARTES DE SAN FERNANDO (1815-1858)}

El listado de los maestros de obras que a continuación se detallan, se ha obtenido de la consulta de numerosos legajos del archivo de las Real Academia de Bellas Artes de San Fernando. El inventario se ha realizado con una pretendida finalidad pragmática: facilitar al estudioso la localización de los expedientes de estos profesionales que obtuvieron sus títulos en el Instituto madrileño. En estas listas primero se reseña el legajo en el que se encuentra el expediente de cada maestro de obra y, a continuación el nombre del mismo, el lugar de nacimiento, la junta ordinaria en que fueron aprobados y la junta de examen. Además, los números de los tres temas que le salieron al azar, de los cuales el aspirante tenía que elegir uno, el cual era el que realizaba como ejercicio y, la denominada prueba de pensado o informe práctico facultativo. Los planos que tuvieron que presentar con esta prueba, así como los realizados en la Academia, se encuentran en la Sala de Planos de San Fernando. Lleva, asimismo, el apartado de PROV. (Provincia) cuya numeración corresponde a los actuales códigos provinciales. Esta numeración permite averiguar, por ejemplo, cuántos maestros de obras que han

34 Expediente de Pedro deL VILLAR y VILLARINO. Leg.: 19-5/2

35 Ibídem. Expediente de Indalecio ALzAÁ YTURRALDE.

36 Ibídem. Expediente de Eduardo Martínez García.

37 Ibídem. Expediente de Serafín VeRgara y VILLANUEVA

38 Ibídem. Expediente de Ramón LOSADA PÉREZ.

39 ibídem. Expediente Juan Antonio ANTÚNEZ y GaRcía 
obtenido el título son de Madrid (28), Barcelona (08), Granada (18) 0 de Zaragoza (50).

En estas pruebas se encuentran las bases ideológicas para el estudio de las distintas tipologías arquitectónicas, así como los temas que preocupaban a la Academia y al Estado al doble vínculo conceptual y de necesidades edificatorias en aquella España que salía de una sangrienta guerra y caminaba hacia una nueva mentalidad, tanto política, económica, como social y cuyo lenguaje arquitectónico nos narra esa realidad aunque sea en arquitectura de proyecto.

Se ha podido comprobar, además, que un gran número de estos diplomados, han seguido estudios superiores y, que han conseguido 24 de ellos el título de arquitecto y dos el de académico de mérito. Después de la fundación de la Escuela Especial de Arquitectura y de la aprobación del último reglamento de 16 de julio de 1852, también lo que se observa es que muchos maestros de obras también consiguen la titulación de Directores de caminos vecinales, cuyos estudios eran iguales los dos primeros años y diferente únicamente el tercer año, con lo cual con un año más de estudios y el abono de quinientos reales ${ }^{40}$ conseguían la otra titulación. No son pues, unos simples prácticos en la Arquitectura, sino unos verdaderos profesionales -igual que los arquitectos-, aunque con menos conocimientos científicos por sus menos estudios y más expertos en la práctica arquitectónica, por su trabajo a pie de obra.

40 Reglamento para las enseñanzas de Maestros de Obras, Directores de Caminos Vecinales y Agrimensores. Artítculo 4. ${ }^{\circ}$ A.A.S.F. Leg.: 23-4/2. 


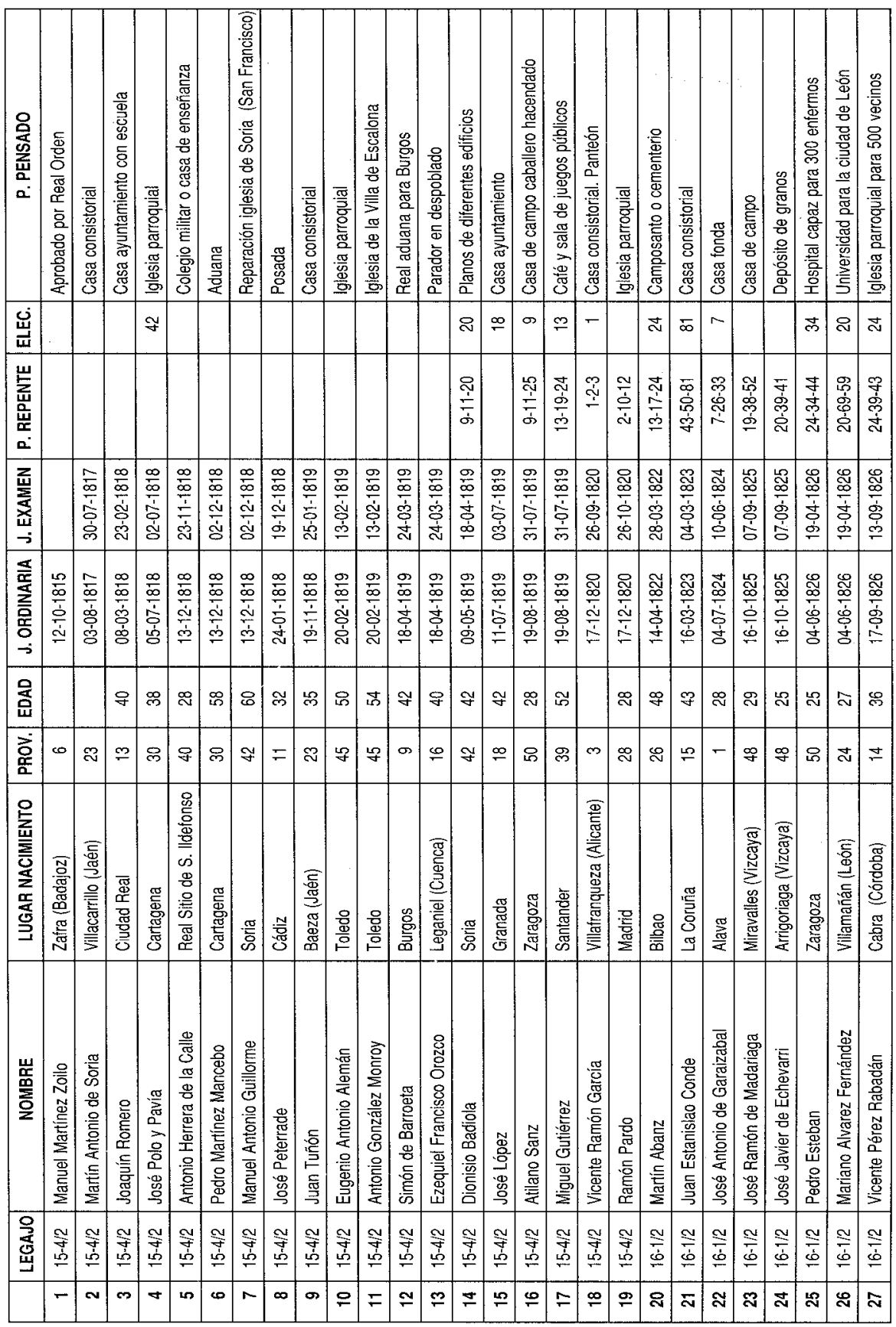




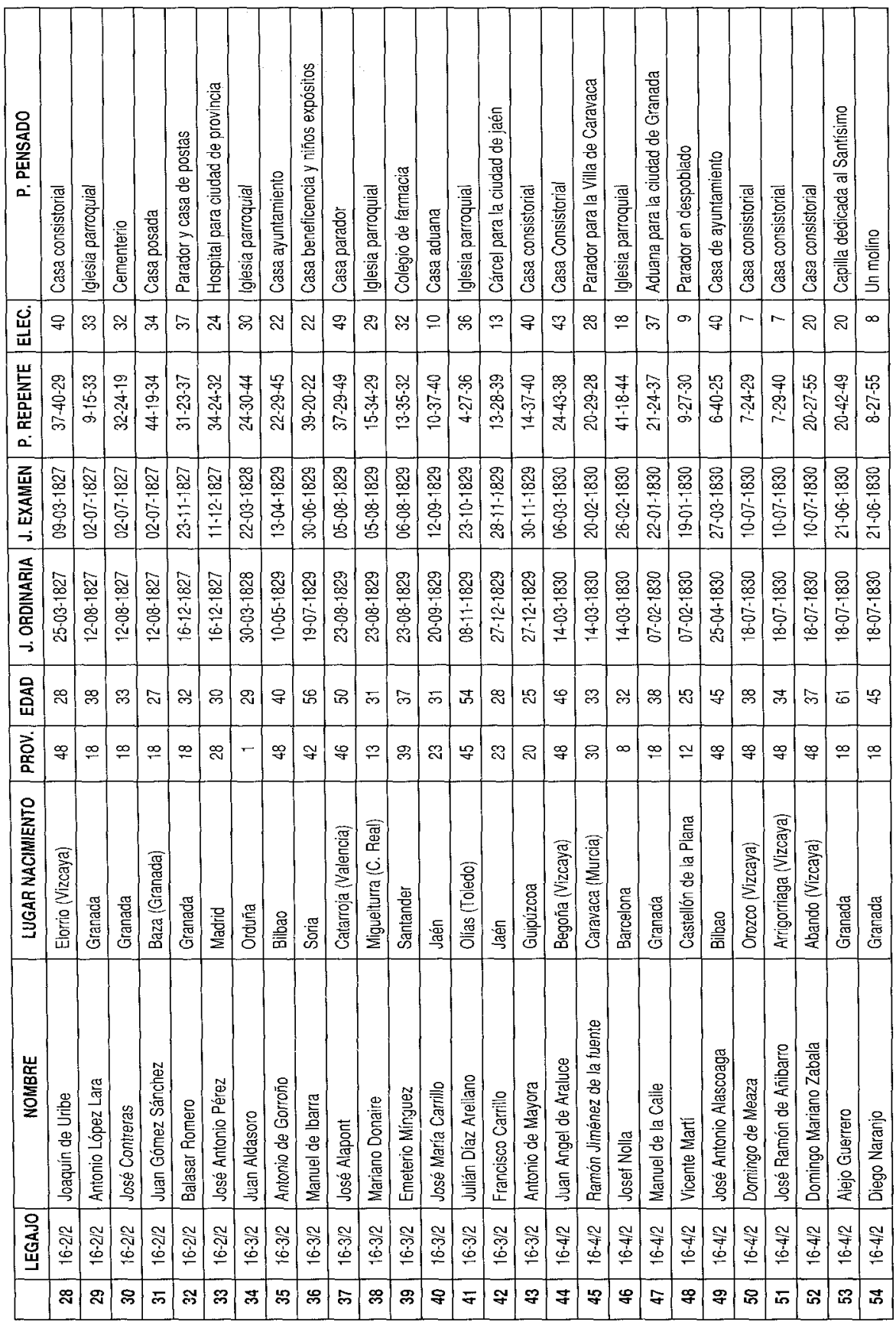




\begin{tabular}{|c|c|c|c|c|c|c|c|c|c|c|c|c|c|c|c|c|c|c|c|c|c|c|c|c|c|c|}
\hline $\begin{array}{l}8 \\
\frac{\partial}{\alpha} \\
\frac{0}{0} \\
\text { 㟔 } \\
\text { م. }\end{array}$ & 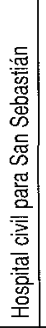 & 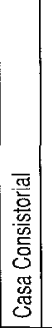 & 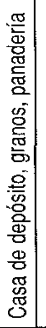 & 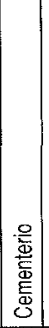 & 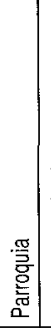 & 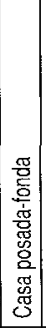 & 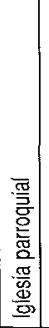 & 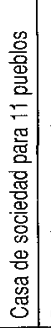 & 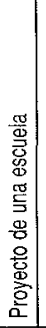 & 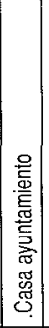 & 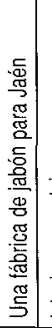 & 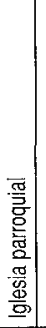 & 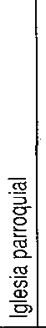 & 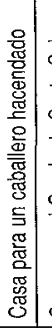 & 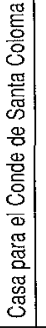 & 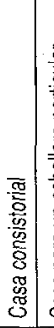 & 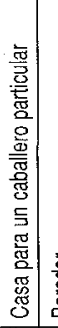 & 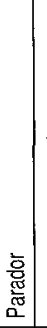 & 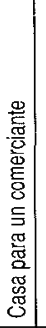 & 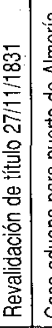 & 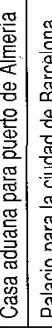 & 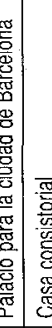 & 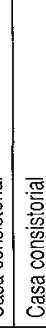 & 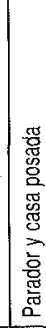 & 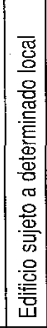 & 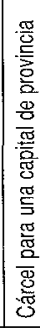 \\
\hline 岃 & $\bar{m}$ & & $\mathbb{N}$ & $\stackrel{\infty}{\sim}$ & g & $=$ & $\infty$ & o & 으 & 웅 & N. & 寸 & 疋 & $\stackrel{\infty}{\infty}$ & 黑 & $F$ & $=0$ & f & $\stackrel{\leftrightarrow}{\stackrel{2}{*}}$ & & 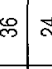 & $\Delta=$ & $\stackrel{\sim}{\sim}$ & 于 & 果 & $m$ \\
\hline 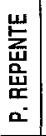 & $\begin{array}{l}\bar{m} \\
\stackrel{\omega}{-} \\
\underline{-1}\end{array}$ & & 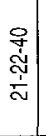 & 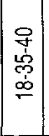 & 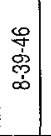 & 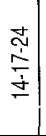 & $\mid \begin{array}{l}\mathscr{P} \\
\stackrel{\sim}{\sim} \\
\dot{J} \\
\sim\end{array}$ & 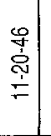 & 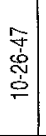 & 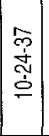 & $\begin{array}{l}\approx \\
\frac{\sim}{\sim} \\
\frac{\sigma}{\sim}\end{array}$ & 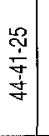 & $\begin{array}{c}9 \\
⿱ \\
o \\
o ̛ ⿱ 宀 \\
o\end{array}$ & $\begin{array}{l}\stackrel{9}{1} \\
\text { o. } \\
\end{array}$ & \begin{tabular}{c}
0 \\
0 \\
0 \\
0 \\
\multirow{j}{N}{}
\end{tabular} & $\begin{array}{l}\hat{y} \\
\dot{y} \\
\dot{f}\end{array}$ & 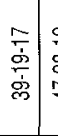 & $\begin{array}{l}\frac{\sigma}{0} \\
0 \\
0 \\
\sigma \\
\sigma\end{array}$ & 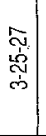 & & & 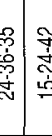 & 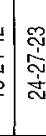 & $\begin{array}{l}\text { 울 } \\
\text { 守 } \\
\text { क् }\end{array}$ & 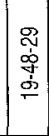 & $\begin{array}{l}\overline{\text { du }} \\
\text { d. }\end{array}$ \\
\hline 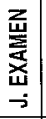 & 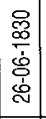 & & $\begin{array}{l}8 \\
\stackrel{8}{0} \\
\frac{0}{0} \\
\stackrel{0}{0} \\
\vdots\end{array}$ & 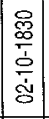 & 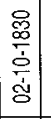 & 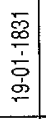 & 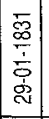 & 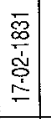 & 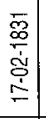 & 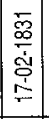 & $\begin{array}{l}\overline{\mathscr{D}} \\
\dot{j} \\
\dot{+} \\
\dot{g} \\
\dot{g}\end{array}$ & 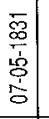 & 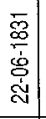 & 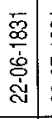 & 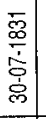 & 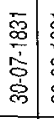 & 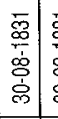 & 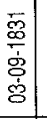 & 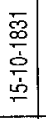 & & 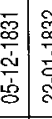 & 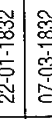 & 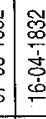 & 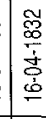 & 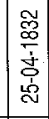 & 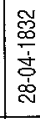 \\
\hline 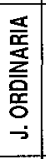 & 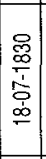 & 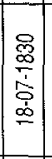 & 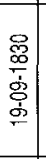 & 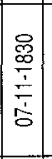 & $\mid \begin{array}{c}0 \\
0 \\
\frac{0}{1} \\
\frac{1}{1} \\
\frac{1}{0}\end{array}$ & 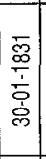 & 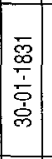 & 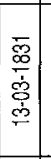 & 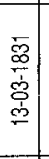 & 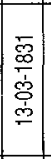 & 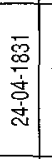 & 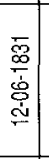 & 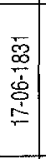 & 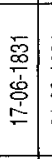 & $\begin{array}{l}\bar{\infty} \\
\bar{\infty} \\
\dot{\phi} \\
\dot{c} \\
\bar{c}\end{array}$ & 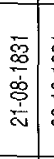 & $\begin{array}{l}\bar{m} \\
\frac{\infty}{0} \\
\overline{0} \\
\overline{\dot{g}}\end{array}$ & $\begin{array}{l}\bar{c} \\
\frac{0}{0} \\
\stackrel{0}{0} \\
\frac{3}{8}\end{array}$ & $\frac{\bar{\delta}}{\frac{\bar{g}}{\frac{1}{5}}}$ & & 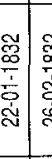 & 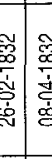 & 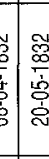 & 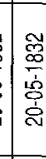 & 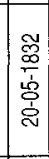 & 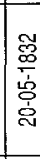 \\
\hline 宫 & 志 & 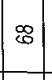 & 8 & $\bar{m}$ & ৪্ & $\bar{\nabla}$ & 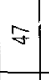 & लि & $\mathscr{\infty}$ & $\stackrel{\infty}{\sim}$ & i & $\stackrel{\sim}{\sim}$ & $\ddot{m}$ & $\approx$ & 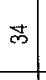 & ले & m & $\stackrel{\sim}{\sim}$ & ले & $\approx$ & ते & is & $\bar{n}$ & L & 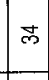 & $\stackrel{\infty}{\approx}$ \\
\hline $\begin{array}{l}\overrightarrow{\vec{z}} \\
\text { 器 }\end{array}$ & ని & & 舟 & 80 & $\mp$ & স্লে & 学 & 喿 & 吕 & $\approx$ & $\mathscr{N}$ & \& & $\infty$ & $\infty$ & $\infty$ & 尺ి & $\infty$ & 品 & $\infty$ & $=$ & 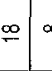 & $\infty$ & 29 & ฉి & $\infty$ & $\stackrel{\infty}{q}$ \\
\hline 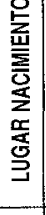 & 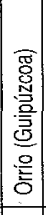 & 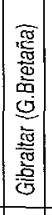 & 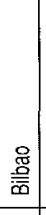 & \begin{tabular}{|l|}
$\frac{\pi}{0}$ \\
$\underline{\Gamma}$ \\
\end{tabular} & 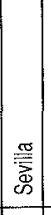 & 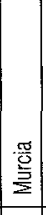 & 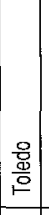 & 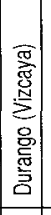 & 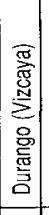 & 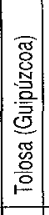 & 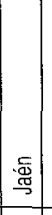 & \begin{tabular}{|l} 
\\
\\
\end{tabular} & 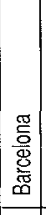 & 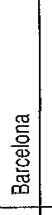 & 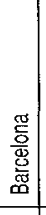 & 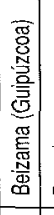 & 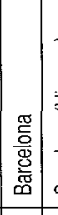 & 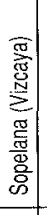 & 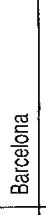 & 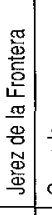 & & 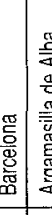 & 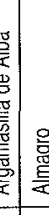 & 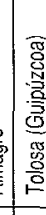 & 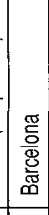 & $\begin{array}{l}\frac{\mathbb{8}}{3} \\
\overline{\overline{0}}\end{array}$ \\
\hline $\begin{array}{l}\text { 誉 } \\
\text { 帘 } \\
\text { 운 }\end{array}$ & 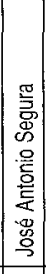 & 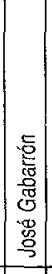 & 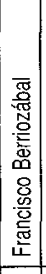 & 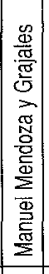 & 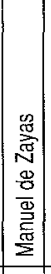 & 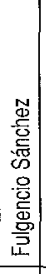 & 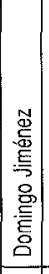 & 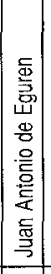 & 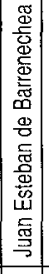 & 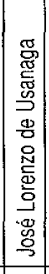 & 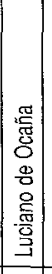 & 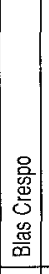 & 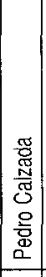 & 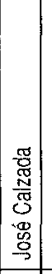 & 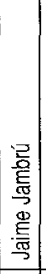 & 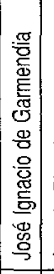 & 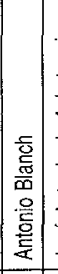 & 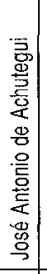 & 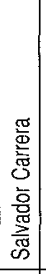 & 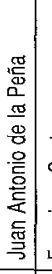 & 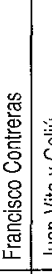 & 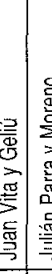 & 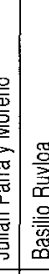 & 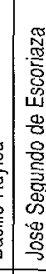 & 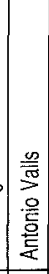 & 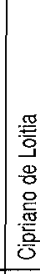 \\
\hline \begin{tabular}{|l|} 
预 \\
嵒 \\
\end{tabular} & $\begin{array}{l}\tilde{y} \\
\dot{y} \\
\underline{\underline{\theta}}\end{array}$ & 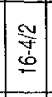 & 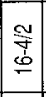 & 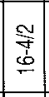 & 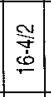 & 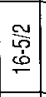 & 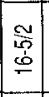 & \begin{tabular}{|c|} 
\\
1 \\
0 \\
0 \\
-1 \\
\end{tabular} & 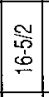 & 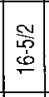 & 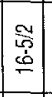 & 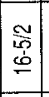 & 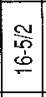 & 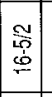 & 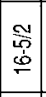 & \begin{tabular}{|c}
$c$ \\
0 \\
0 \\
0 \\
0 \\
\end{tabular} & 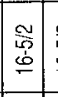 & 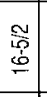 & 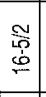 & $\begin{array}{l}\frac{N}{0} \\
\underline{0} \\
\stackrel{0}{0} \\
\end{array}$ & 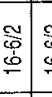 & 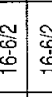 & 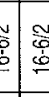 & 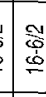 & $\begin{array}{l}\frac{y}{3} \\
\dot{0} \\
\underline{0} \\
\end{array}$ & 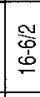 \\
\hline & 40 & 品 & in & : & $\mathbb{B}$ & 8 & 5 & $\mathbf{8}$ & 8 & 8 & 另 & $\Phi$ & 6 & 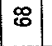 & : & $R$ & $\bar{\sigma}$ & 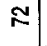 & 2 & $\mathbb{R}$ & 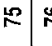 & $\stackrel{7}{*}$ & $=\stackrel{\infty}{r}$ & $R$ & 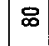 & $\infty$ \\
\hline
\end{tabular}




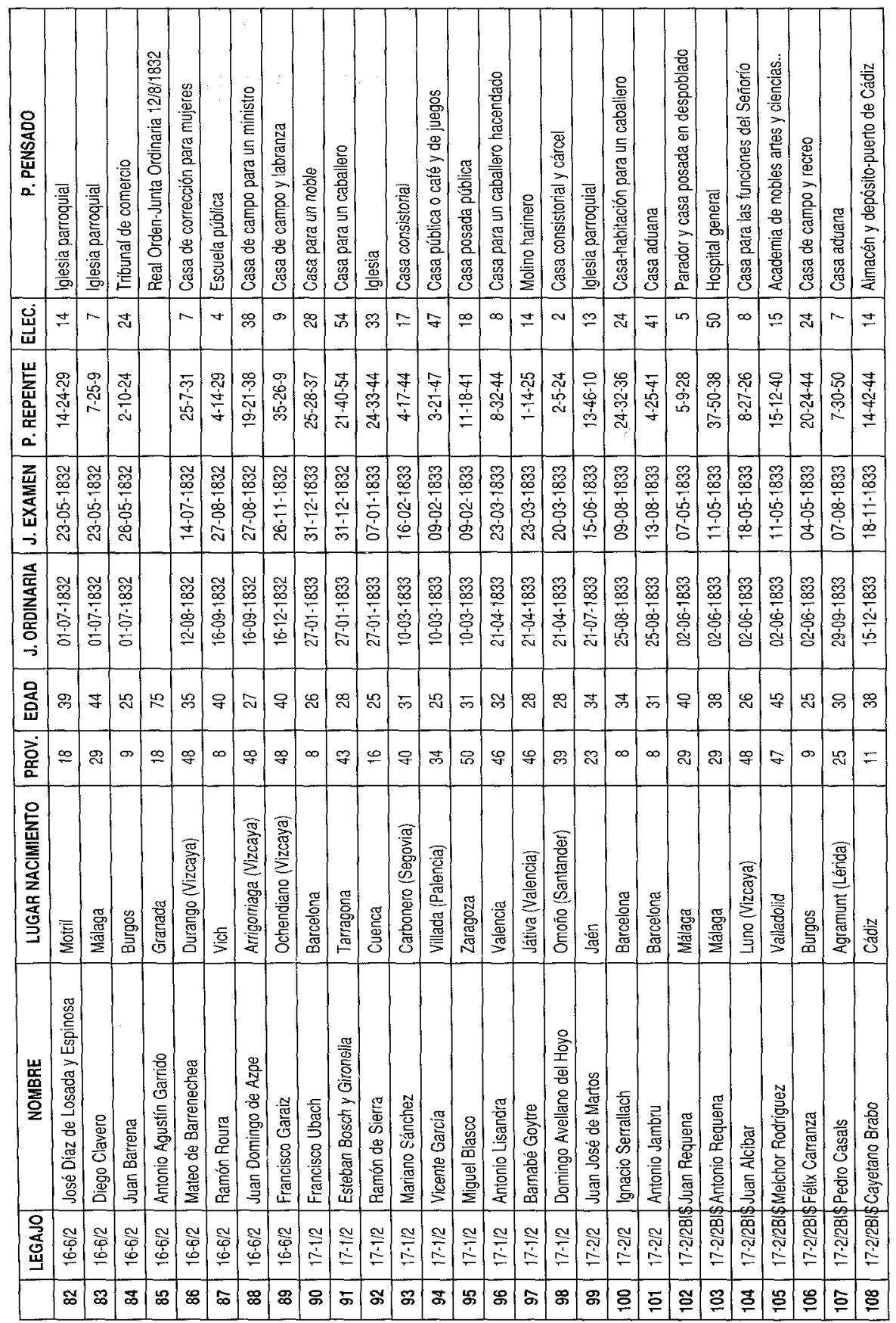




\begin{tabular}{|c|c|c|c|c|c|c|c|c|c|c|c|c|c|c|c|c|c|c|c|c|c|c|c|c|c|}
\hline 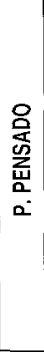 & 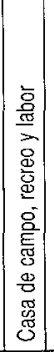 & 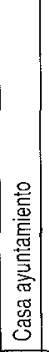 & 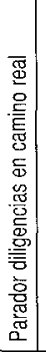 & 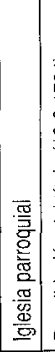 & 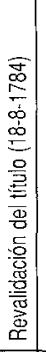 & 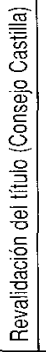 & 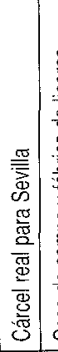 & 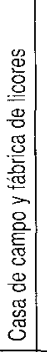 & 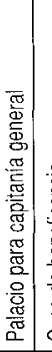 & 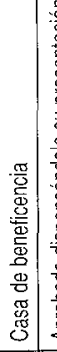 & 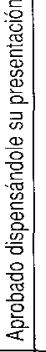 & 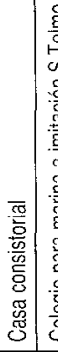 & 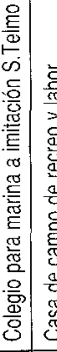 & 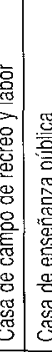 & 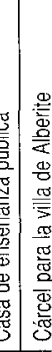 & 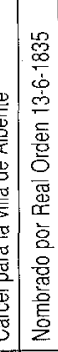 & 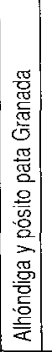 & 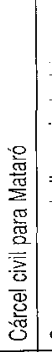 & 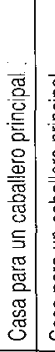 & 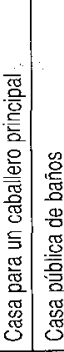 & 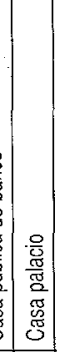 & 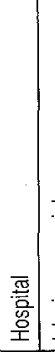 & 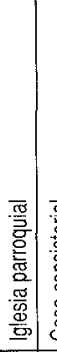 & & 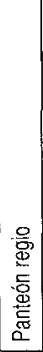 \\
\hline 总 & $\Sigma$ & $\infty$ & $\overline{\text { ल }}$ & m্ল & & & 80 & $\infty$ & 足 & $\simeq$ & & $\stackrel{m}{=}$ & of $=$ & $\stackrel{2}{*}$ & $\begin{array}{r}y \\
y\end{array}$ & & $\tilde{\mathrm{s}}$ & $\approx$ & F & \begin{tabular}{l|l} 
& $\stackrel{\infty}{\sim}$
\end{tabular} & $\approx$ & 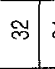 & $\bar{N}:$ & $\mathbb{N}$ & 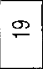 \\
\hline 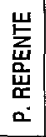 & 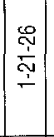 & 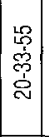 & $\begin{array}{l}\frac{0}{1} \\
\stackrel{p}{p} \\
?\end{array}$ & 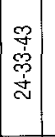 & & & 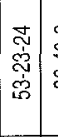 & 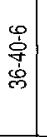 & $\begin{array}{l}\text { 导 } \\
\text { dे } \\
\text { ஸे }\end{array}$ & 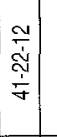 & & 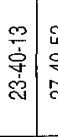 & 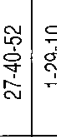 & 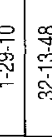 & 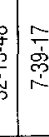 & & $\mid \begin{array}{c}\frac{9}{\sigma} \\
\frac{1}{1} \\
\frac{1}{\Delta} \\
\end{array}$ & 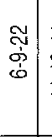 & 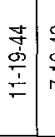 & 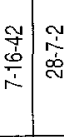 & 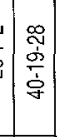 & $\begin{array}{l}0 \\
\infty \\
\infty \\
\infty \\
\infty \\
\infty\end{array}$ & \begin{tabular}{l} 
o \\
\multirow{i}{*}{} \\
ஸे
\end{tabular} & & 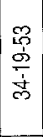 \\
\hline 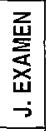 & 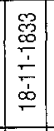 & 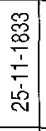 & 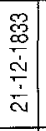 & \begin{tabular}{|c|} 
\\
0 \\
0 \\
$\vdots$ \\
$\vdots$ \\
0 \\
0 \\
0 \\
\end{tabular} & & & 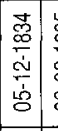 & 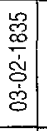 & 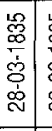 & 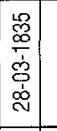 & & 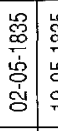 & 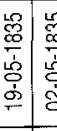 & 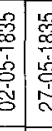 & 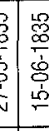 & & 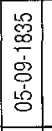 & 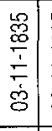 & 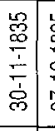 & 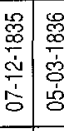 & 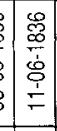 & 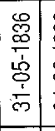 & 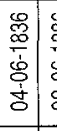 & $\begin{array}{l}0 \\
0 \\
0 \\
0 \\
0 \\
0 \\
0 \\
\end{array}$ & 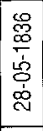 \\
\hline 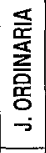 & 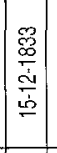 & 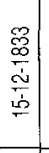 & 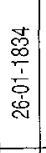 & 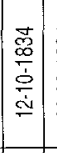 & 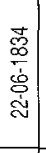 & 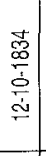 & 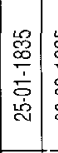 & 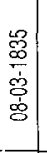 & 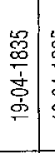 & 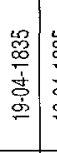 & 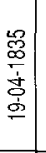 & 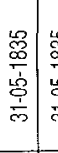 & 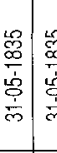 & 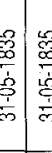 & 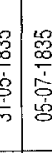 & 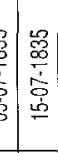 & 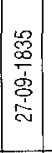 & 怘 & 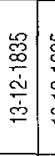 & 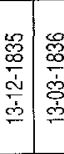 & 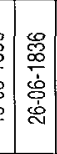 & 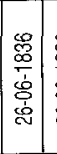 & 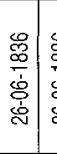 & $\begin{array}{l}0 \\
0 \\
\Phi \\
\dot{\phi} \\
\dot{d} \\
\dot{\Phi}\end{array}$ & 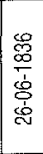 \\
\hline 옿 & $q$ & ले & $\stackrel{\sim}{\sim}$ & $\stackrel{\infty}{\sim}$ & $?$ & & 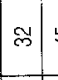 & 学 & ले & $\stackrel{\infty}{\infty}$ & & F & F & $\approx 7$ & $\begin{array}{l}y \\
y\end{array}$ & $\circ ?$ & 吉 & 夺 & $\vec{m}$ & $\bar{m}$ & $\stackrel{\infty}{\sim}$ & 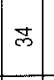 & $\stackrel{2}{\sim}$ & 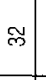 & : \\
\hline \begin{tabular}{|l} 
产 \\
产
\end{tabular} & $=$ & 戹 & $\approx$ & $\stackrel{\infty}{q}$ & g & $\mathbb{N}$ & $\mp$ & $\mp$ & $\infty$ & $\infty$ & $\mathbb{N}$ & 于 & $\mp 18$ & $f=$ & $=\approx$ & S) & $\stackrel{\infty}{\sim}$ & $\infty$ & $\infty$ & $\infty \quad \infty$ & o) & $\bar{\gamma}$ & क & $\infty$ & $\tilde{m}$ \\
\hline 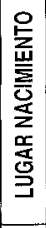 & $\left|\begin{array}{l}\frac{N}{5} \\
\stackrel{5}{5} \\
\end{array}\right|$ & 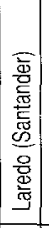 & 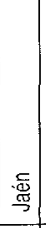 & $\begin{array}{l}\text { 욤 } \\
\stackrel{0}{\bar{m}} \\
\end{array}$ & 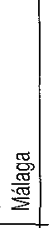 & 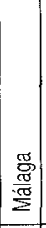 & $\mid$ & 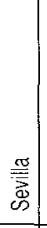 & 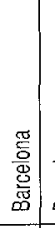 & 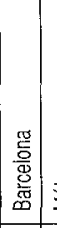 & 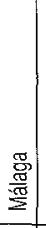 & 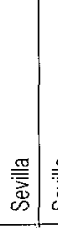 & & 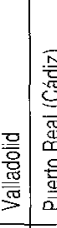 & 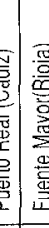 & 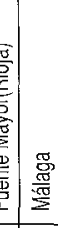 & 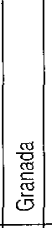 & 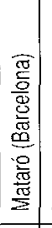 & 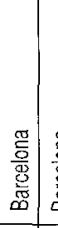 & 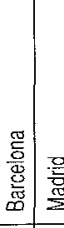 & 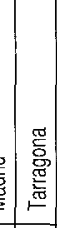 & 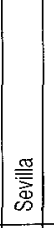 & 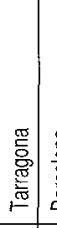 & 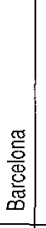 & 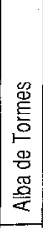 \\
\hline \begin{tabular}{|l} 
崖 \\
产 \\
o \\
\end{tabular} & 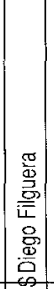 & 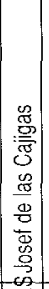 & 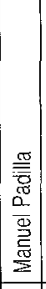 & 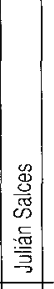 & 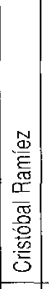 & 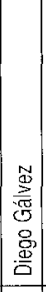 & 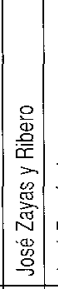 & 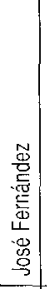 & 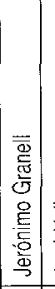 & 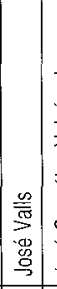 & 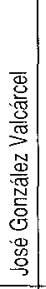 & 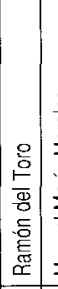 & 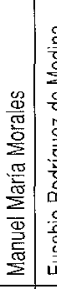 & 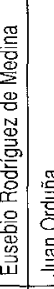 & 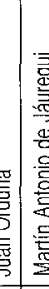 & 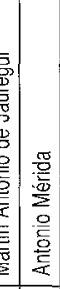 & 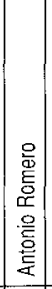 & 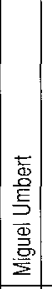 & 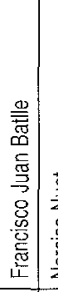 & 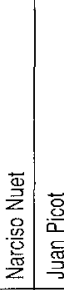 & 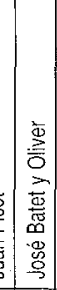 & 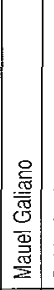 & 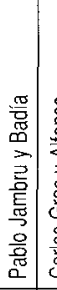 & 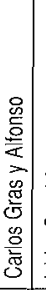 & 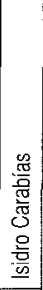 \\
\hline \begin{tabular}{|l} 
옹 \\
总
\end{tabular} & 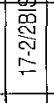 & 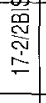 & $\mid \begin{array}{c}N \\
\stackrel{N}{5} \\
\stackrel{N}{\sim}\end{array}$ & 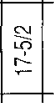 & $\begin{array}{l}\frac{\widetilde{T}}{5} \\
\stackrel{5}{\leftarrow}\end{array}$ & 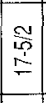 & $\mid$ & 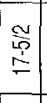 & $\stackrel{\frac{N}{5}}{\stackrel{5}{5}}$ & $\mid$ & 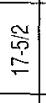 & $\mid$\begin{tabular}{l}
0 \\
0 \\
0 \\
\hdashline
\end{tabular} & 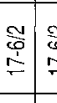 & 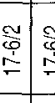 & 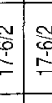 & 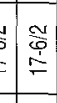 & 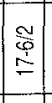 & 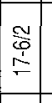 & 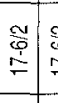 & 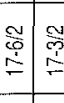 & 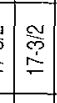 & $\begin{array}{l}\frac{\tilde{y}}{\mathrm{p}} \\
\stackrel{?}{=}\end{array}$ & $\begin{array}{l}\frac{9}{5} \\
\frac{5}{\square}\end{array}$ & $\begin{array}{l}\frac{N}{2} \\
\frac{T}{?} \\
\frac{1}{5}\end{array}$ & $\begin{array}{l}\frac{N}{p} \\
\stackrel{p}{r}\end{array}$ \\
\hline & $\stackrel{g}{\circ}$ & 움 & $\Xi$ & $\cong$ & $\stackrel{m}{\rightleftharpoons}$ & $\stackrel{⿱ 亠 䒑}{\doteqdot}$ & $\stackrel{20}{2}$ & $\stackrel{\circ}{\risingdotseq}$ & $\cong$ & $\stackrel{\infty}{\rightleftharpoons}$ & $\stackrel{\circ}{\rightleftharpoons}$ & 요 & $\bar{\tau}$ & 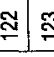 & $\stackrel{2}{2}$ & $\stackrel{2}{\stackrel{2}{N}}$ & $\stackrel{9}{9}$ & 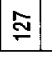 & 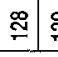 & 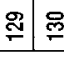 & $\bar{p}$ & 总 & $\stackrel{\mathscr{m}}{=}$ & & $\stackrel{2}{\mathrm{~m}}$ \\
\hline
\end{tabular}




\begin{tabular}{|c|c|c|c|c|c|c|c|c|c|c|c|c|c|c|c|c|c|c|c|c|c|c|c|c|c|}
\hline 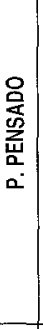 & 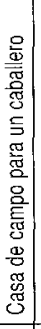 & 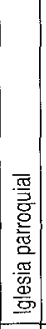 & 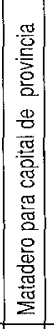 & 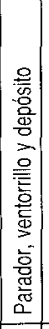 & 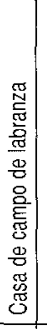 & 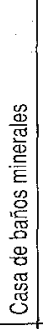 & 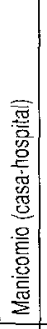 & 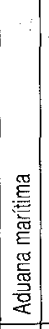 & 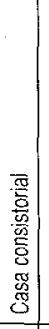 & 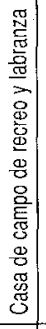 & 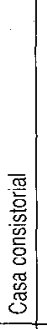 & 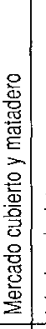 & 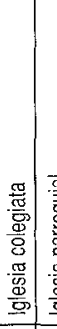 & 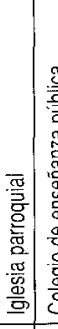 & 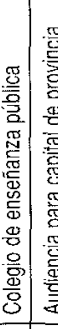 & 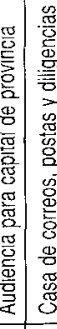 & 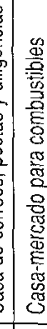 & 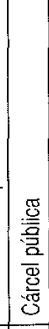 & 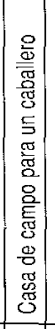 & 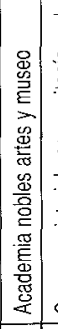 & 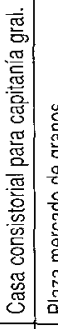 & 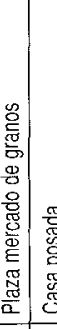 & 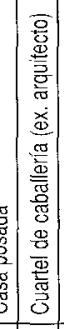 & 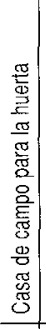 & $\begin{array}{l}\sum \\
c \dot{0} \\
g \\
g \\
c\end{array}$ \\
\hline 悹 & $\infty$ & $\infty$ & $\bar{\gamma}$ & $\approx$ & 示 & $\overline{50}$ & 品 & $\infty$ & $n$ & $\simeq$ & $f$ & $\sigma$ & $=0$ & \begin{tabular}{l|l} 
& a
\end{tabular} & $\mathbb{N}$ & $\approx \approx$ & $\pi$ & $n$ & $\Phi$ & \& & $\stackrel{\infty}{\circ}$ & $\stackrel{\sim}{\circ}$ & & $\because$ & \\
\hline 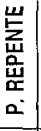 & 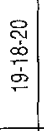 & 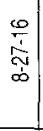 & 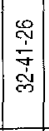 & 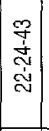 & $\begin{array}{l}\frac{y}{0} \\
\dot{0} \\
\frac{1}{m}\end{array}$ & $\begin{array}{l}\hat{1} \\
\frac{1}{2} \\
\stackrel{0}{0}\end{array}$ & 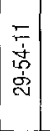 & 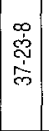 & $\begin{array}{l}\stackrel{+}{d} \\
\stackrel{d}{\infty}\end{array}$ & 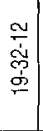 & 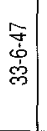 & 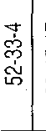 & 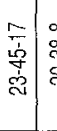 & 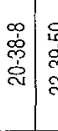 & 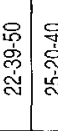 & 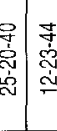 & 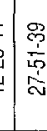 & $\frac{\frac{1}{2}}{\frac{1}{m}}$ & $\mid$\begin{tabular}{c}
$\hat{y}$ \\
\multirow{y}{f}{} \\
$\dot{\sigma}$
\end{tabular} & 守 & \begin{tabular}{l|l}
$\sigma$ \\
$\dot{m}$ \\
$\dot{m}$ \\
$\dot{\tilde{m}}$
\end{tabular} & 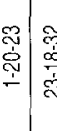 & 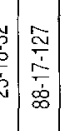 & 离 & \\
\hline 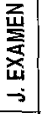 & $\begin{array}{l}0 \\
0 \\
0 \\
0 \\
0 \\
\dot{0} \\
\delta\end{array}$ & 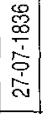 & 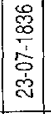 & 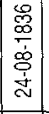 & $\begin{array}{l}\infty \\
\infty \\
\infty \\
\vdots \\
\vdots \\
\dot{0} \\
0\end{array}$ & $\begin{array}{l}\overrightarrow{0} \\
0 \\
0 \\
0 \\
\vdots \\
0 \\
0\end{array}$ & 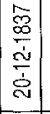 & 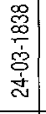 & 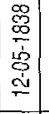 & 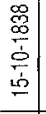 & 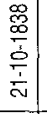 & 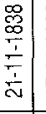 & 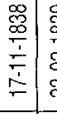 & 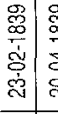 & 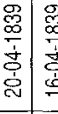 & 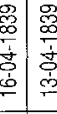 & 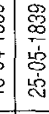 & 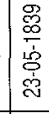 & 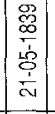 & 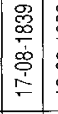 & 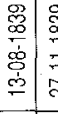 & 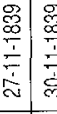 & 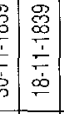 & 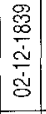 & \\
\hline 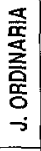 & 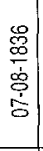 & 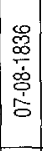 & $\left|\begin{array}{c}\mathscr{0} \\
\frac{0}{0} \\
\dot{0} \\
\vdots \\
\vdots \\
\sigma\end{array}\right|$ & 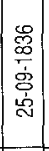 & 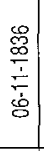 & 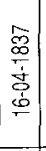 & $\mid \begin{array}{c}\infty \\
0 \\
\frac{1}{1} \\
\frac{1}{\alpha} \\
\frac{1}{N}\end{array}$ & 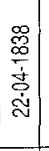 & $\mid$ & 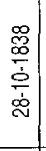 & 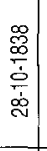 & 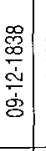 & 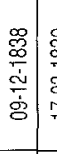 & 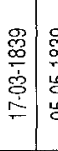 & 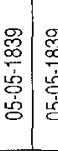 & 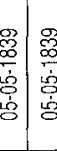 & 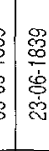 & 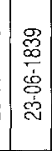 & 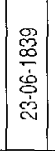 & 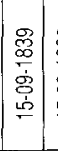 & 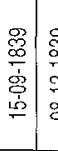 & 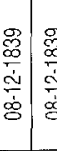 & 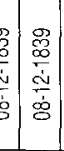 & 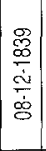 & 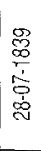 \\
\hline 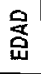 & $\stackrel{9}{\triangle}$ & $\stackrel{0}{\sim}$ & 票 & 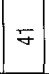 & $\begin{array}{l}10 \\
0\end{array}$ & $\stackrel{2}{\triangle 1}$ & 8 & 尺 & $c$ & $\stackrel{\infty}{q}$ & $\stackrel{\sim}{\sim}$ & $m$ & $\therefore$ & $8:$ & ले & $m$ & 3. & m & m & क् & 焉 & $\ddot{m}$ & of & $\triangle$ & \\
\hline $\begin{array}{l}\overrightarrow{\mathrm{z}} \\
\text { 品 }\end{array}$ & $\oplus$ & $\stackrel{\infty}{\sim}$ & 尺 & & L & 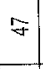 & - & $=$ & $\%$ & $\infty$ & $\infty$ & $g$ & $m$ & 尺 & $\infty q$ & $8 \infty$ & \% & $\mathscr{F}$ & $\stackrel{2}{\sim}$ & ₹ & g & $\infty ল$ & $m$ g & $m$ & $\mathbb{N}$ \\
\hline 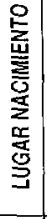 & 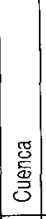 & 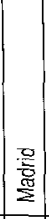 & 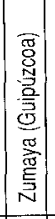 & 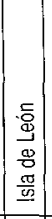 & 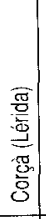 & 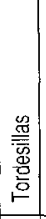 & 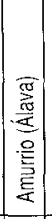 & 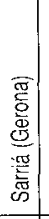 & 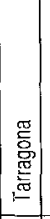 & 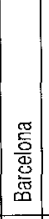 & 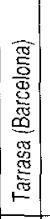 & 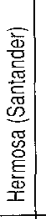 & 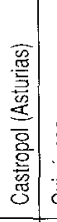 & 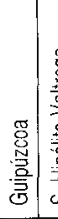 & 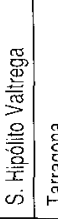 & 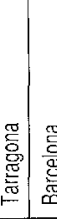 & 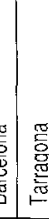 & 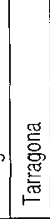 & 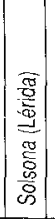 & 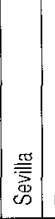 & 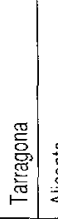 & 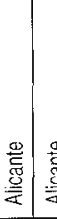 & 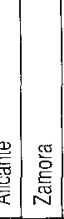 & 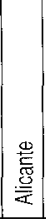 & 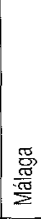 \\
\hline $\begin{array}{l}\text { 営 } \\
\text { 产 } \\
\text { 올 }\end{array}$ & 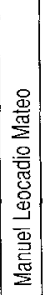 & 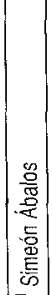 & 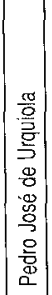 & 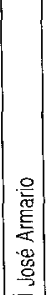 & 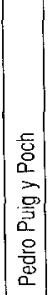 & 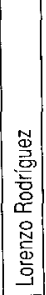 & 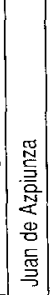 & 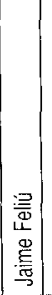 & 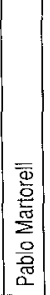 & 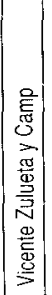 & 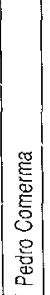 & 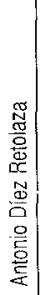 & 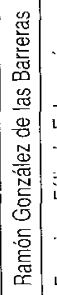 & 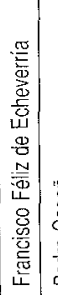 & 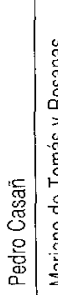 & 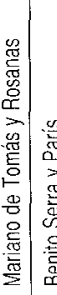 & 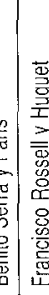 & 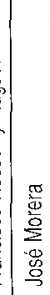 & 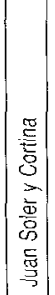 & 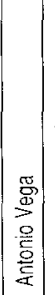 & 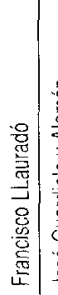 & 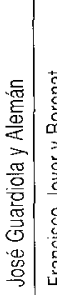 & 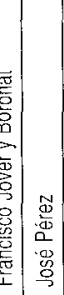 & 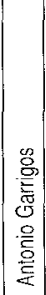 & 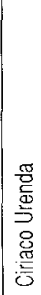 \\
\hline \multirow[t]{2}{*}{ 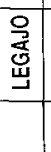 } & $\begin{array}{l}\stackrel{N}{m} \\
\stackrel{m}{\leftarrow}\end{array}$ & $\frac{2}{9}$ & $\frac{\widetilde{v}}{\mathbf{m}}$ & $\mid \begin{array}{c}\frac{1}{5} \\
\stackrel{5}{\sim}\end{array}$ & 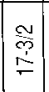 & $\underset{⿱}{\stackrel{Y}{\mathfrak{r}}}$ & 愛 & $\stackrel{\frac{N}{5}}{\stackrel{5}{I}}$ & $\mid \begin{array}{c}\frac{9}{7} \\
\stackrel{5}{5}\end{array}$ & 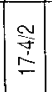 & 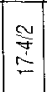 & 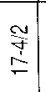 & $\stackrel{\frac{7}{3}}{\stackrel{9}{!}}$ & $\stackrel{\cong}{\stackrel{\infty}{\infty}}$ & 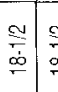 & $\underset{\infty}{\cong} \underset{\infty}{\stackrel{\infty}{\infty}}$ & $\stackrel{9}{\infty}$ & 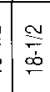 & 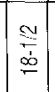 & $\stackrel{\cong}{\check{\infty}}$ & $\frac{y}{\dot{\alpha}}$ & $\underset{\infty}{\cong}$ & 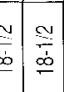 & $\frac{\cong}{\dot{\omega}}$ & 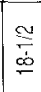 \\
\hline & 息 & 횡 & 总 & 总 & P & $F$ & $\exists$ & 黑 & 寻 & 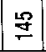 & 昌 & F & $\mid \begin{array}{l}9 \\
\end{array}$ & $g$ & 욘 & 5 & 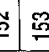 & : & 总 & 总 & 点 & $\stackrel{\infty}{\circ}$ & 8 & $\bar{\Phi}$ & $\stackrel{\infty}{=}$ \\
\hline
\end{tabular}




\begin{tabular}{|c|c|c|c|c|c|c|c|c|c|c|c|c|c|c|c|c|c|c|c|c|c|c|c|c|c|c|}
\hline & 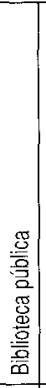 & 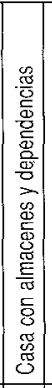 & 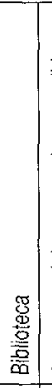 & 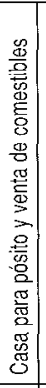 & 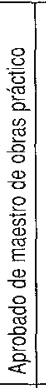 & & 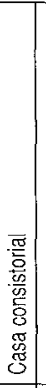 & 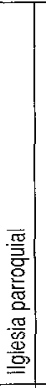 & 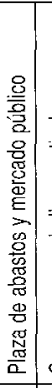 & 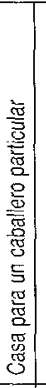 & 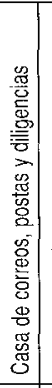 & 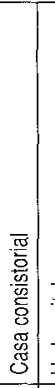 & 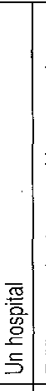 & 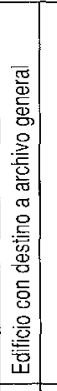 & & 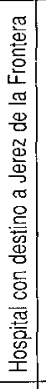 & 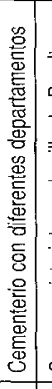 & 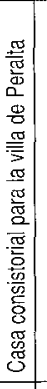 & 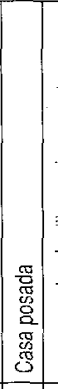 & 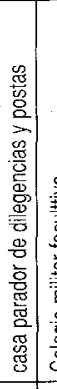 & 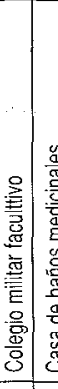 & 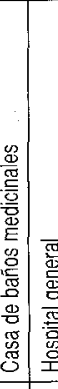 & 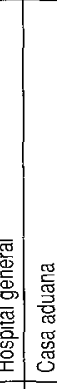 & & 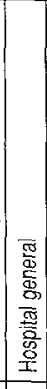 & Ш艹 \\
\hline 总 & $\%$ & 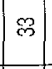 & $\Phi$ & ळ & & & 웅 & F & $\nabla$ & $\sim$ & $\bar{N}$ & $\oplus$ & 子 & 9 & & $\sim$ & 寸 & $\bar{m}$ & $\vec{m}$ & बे & $\mathbb{N} \mid \subsetneq$ & F & 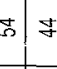 & $\infty$ & $\Phi$ & : \\
\hline 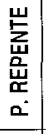 & 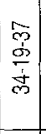 & 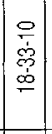 & $\left|\begin{array}{l}\frac{g}{\sigma} \\
\frac{1}{\omega} \\
\dot{\omega} \\
m\end{array}\right|$ & $\begin{array}{l}m \\
m \\
0 \\
\frac{1}{y}\end{array} \mid$ & & & 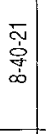 & 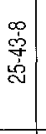 & 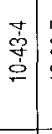 & 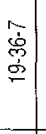 & $\left|\begin{array}{c}\bar{y} \\
\frac{y}{\mathcal{F}} \\
\dot{f}\end{array}\right|$ & 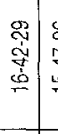 & 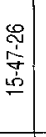 & 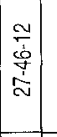 & & 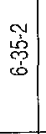 & 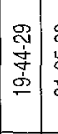 & 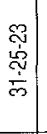 & 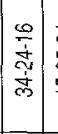 & 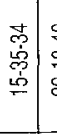 & 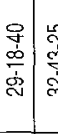 & 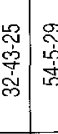 & 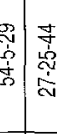 & & & n \\
\hline 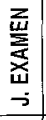 & 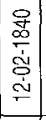 & 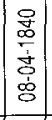 & 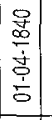 & 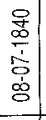 & & & & 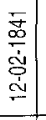 & $\begin{array}{l}\bar{\mp} \\
0 \\
0 \\
0 \\
0 \\
0\end{array}$ & 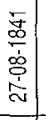 & 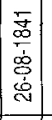 & 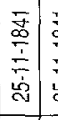 & 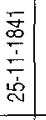 & 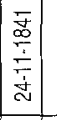 & & 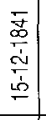 & 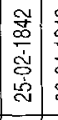 & 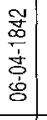 & 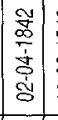 & 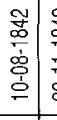 & 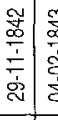 & 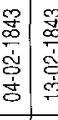 & 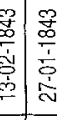 & & & \\
\hline 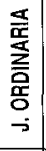 & 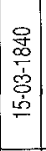 & 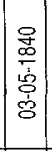 & 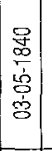 & $\mid$\begin{tabular}{l}
9 \\
0 \\
0 \\
0 \\
0 \\
0 \\
0 \\
\hdashline \\
\end{tabular} & & 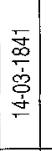 & $\begin{array}{l}\dot{0} \\
\dot{1} \\
\dot{\omega} \\
\vdots \\
\dot{b}\end{array}$ & 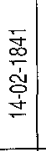 & 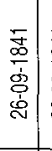 & 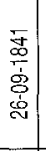 & 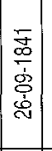 & 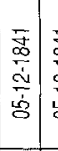 & 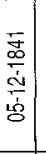 & 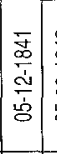 & 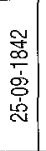 & 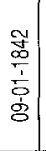 & \begin{tabular}{|}
$\tilde{y}$ \\
0 \\
0 \\
$\dot{0}$ \\
$\dot{0}$ \\
$\dot{0}$ \\
\end{tabular} & 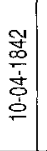 & 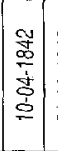 & 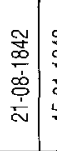 & 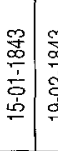 & 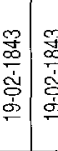 & 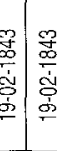 & & 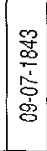 & 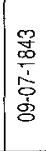 \\
\hline 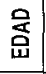 & \& & 泫 & 8 & $\bar{m}$ & & 学 & $\stackrel{\infty}{\infty}$ & 足 & 点 & 点 & 禺 & ल & $\stackrel{\infty}{q}$ & প & ले & y & $\approx$ & $\bar{m}$ & 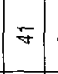 & $\stackrel{\sim}{2}$ & $\stackrel{\sim}{\sim} 1$ & g & बे & $\stackrel{\sim}{\circ}$ & $\mathscr{L}$ & 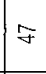 \\
\hline 六 & हि & 寺 & F & 杰 & $\begin{array}{l}\infty \\
\cdots \\
\cdots\end{array}$ & 尺i & $\stackrel{\infty}{q}$ & $\stackrel{\infty}{\sim}$ & $=$ & $=$ & $\infty$ & 羍 & 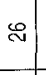 & $\stackrel{\infty}{\sim}$ & $m$ & $F$ & F & $\bar{m}$ & 7 & ष & $\stackrel{\circ}{\circ}$ & \pm & $\approx$ & $\stackrel{\infty}{f}$ & o & $\infty$ \\
\hline 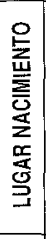 & 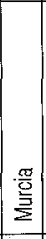 & 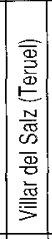 & 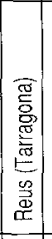 & 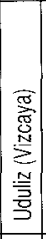 & 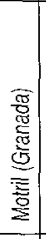 & 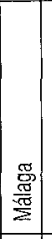 & 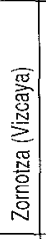 & 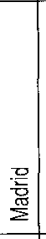 & 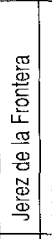 & 愛 & 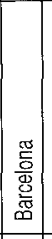 & 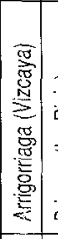 & 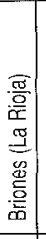 & 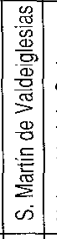 & 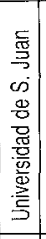 & 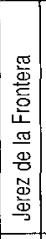 & 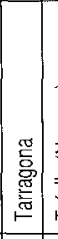 & 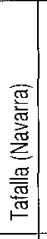 & 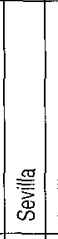 & 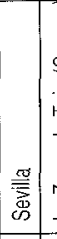 & 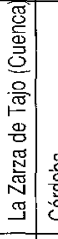 & 悤 & 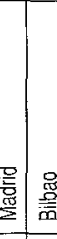 & & 总 & 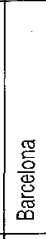 \\
\hline $\begin{array}{l}\text { 崽 } \\
\text { 产 } \\
\text { 은 }\end{array}$ & 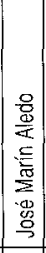 & 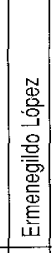 & 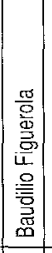 & 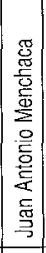 & 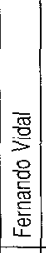 & 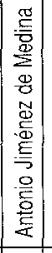 & 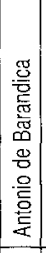 & 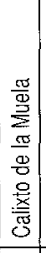 & 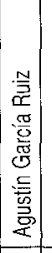 & 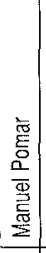 & 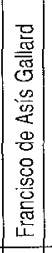 & 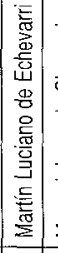 & 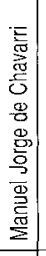 & 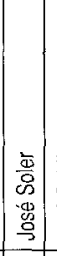 & 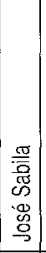 & 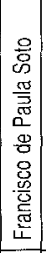 & 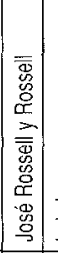 & 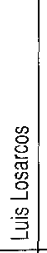 & 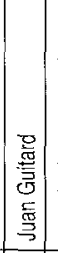 & 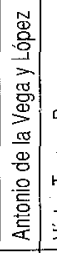 & 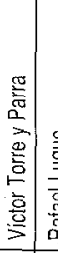 & 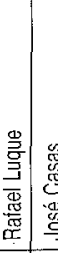 & 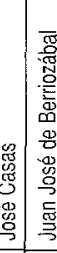 & 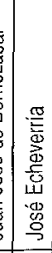 & 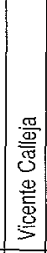 & 4 \\
\hline 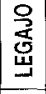 & 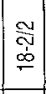 & $\begin{array}{l}\mathbb{N} \\
\mathbb{T} \\
0 \\
0\end{array}$ & 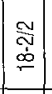 & 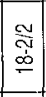 & N & & $\frac{N}{3}$ & 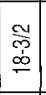 & 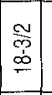 & 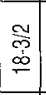 & 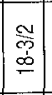 & $\mid$ & 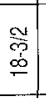 & \begin{tabular}{|l}
$\mathbb{N}$ \\
$\tilde{w}$ \\
$\underline{w}$ \\
\end{tabular} & & 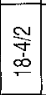 & 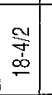 & 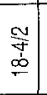 & 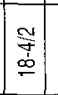 & $\begin{array}{c}f \\
\infty \\
\infty\end{array}$ & 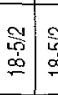 & 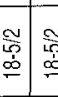 & 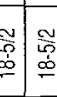 & 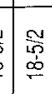 & 芯 & $\mid \begin{array}{l}\qquad \\
0 \\
0 \\
0\end{array}$ \\
\hline & 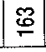 & 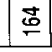 & $\stackrel{0}{\circ}$ & 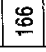 & $\stackrel{\Xi}{-}$ & $\stackrel{\circ}{\stackrel{0}{*}}$ & 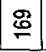 & 으 & $\Sigma$ & $\approx$ & $\cong$ & 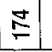 & $\stackrel{\mathfrak{N}}{\stackrel{2}{2}}$ & $1=1$ & & $\stackrel{\mathscr{2}}{=}$ & $\stackrel{2}{2}$ & $\stackrel{\infty}{-}$ & $\bar{D}$ & $\stackrel{2}{\infty}$ & $\stackrel{\mathscr{\infty}}{=}$ & $\underset{\Phi}{ \pm 0}$ & 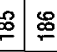 & 产 & 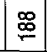 & 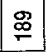 \\
\hline
\end{tabular}




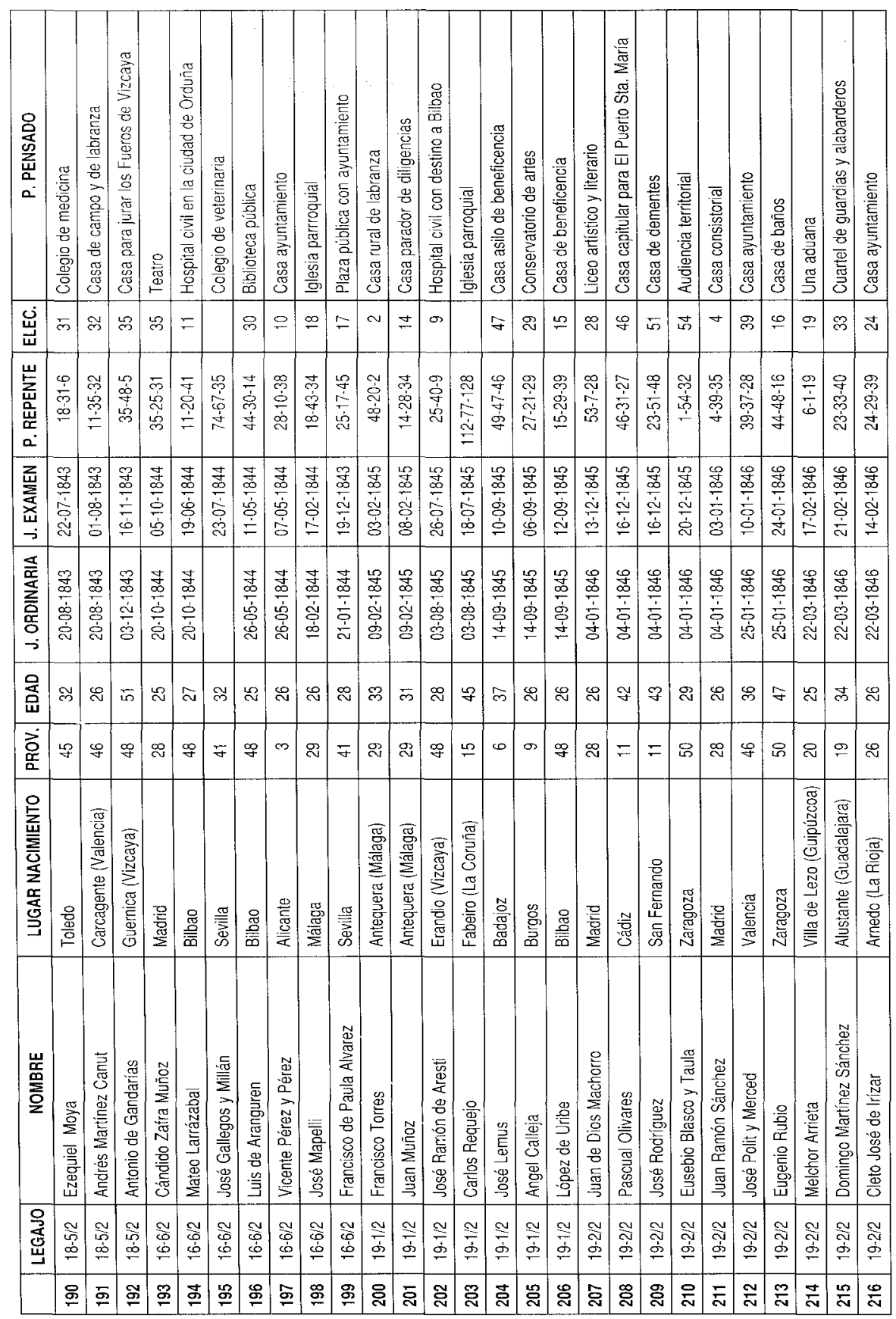




\begin{tabular}{|c|c|c|c|c|c|c|c|c|c|c|c|c|c|c|c|c|c|c|c|c|c|c|c|c|c|c|c|}
\hline 0 & 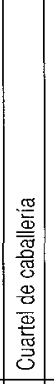 & 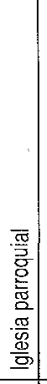 & 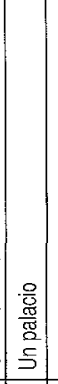 & 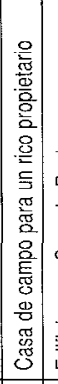 & 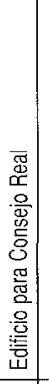 & 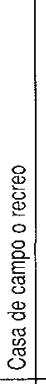 & 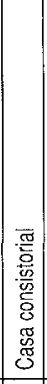 & 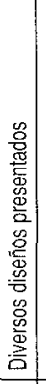 & 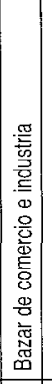 & 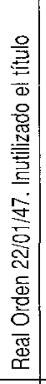 & 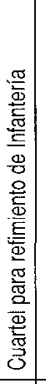 & 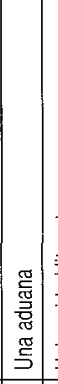 & 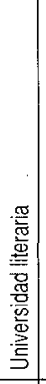 & 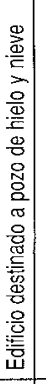 & 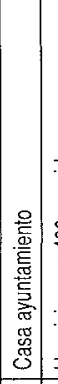 & 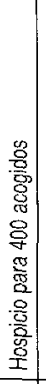 & 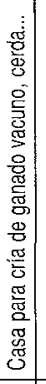 & 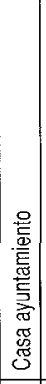 & 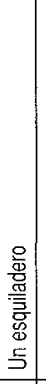 & 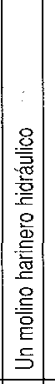 & 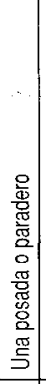 & 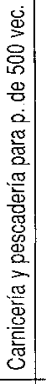 & 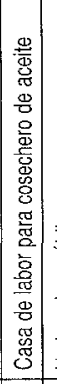 & 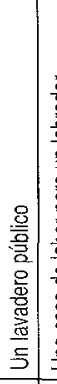 & 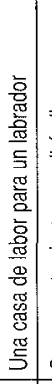 & 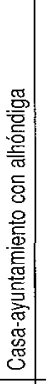 & 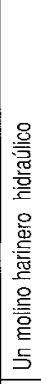 \\
\hline 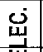 & 寸 & o & 昌 & 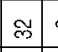 & $\sigma$ & $\stackrel{\circ}{\circ}$ & $\simeq$ & & 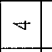 & & 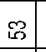 & $\infty$ & & $\sigma$ & 요 & & & & & & & & & & & & \\
\hline 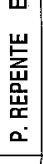 & 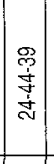 & 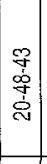 & 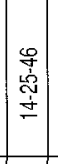 & $\mid \begin{array}{c}\overline{\dot{\alpha}} \\
\grave{\sim} \\
\tilde{c}\end{array}$ & $\left|\begin{array}{l}0 \\
0 \\
0 \\
0 \\
p \\
p\end{array}\right|$ & 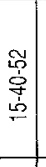 & 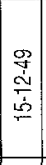 & 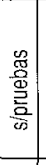 & 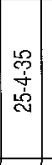 & & 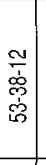 & 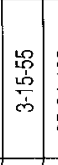 & 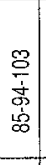 & 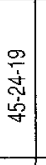 & 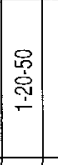 & & \begin{tabular}{c|c}
- & \\
$\vdots$ & \\
$\vdots$ & \\
0 &
\end{tabular} & $\mid$\begin{tabular}{l|}
$\bar{Z}$ \\
$\vdots$ \\
$\dot{C}$ \\
0 \\
0
\end{tabular} & 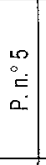 & $\left|\begin{array}{l|}0 \\
0 \\
\Sigma \\
a^{2}\end{array}\right|$ & $\mid \begin{array}{l}J \\
\vdots \\
\Sigma \\
0 \\
\end{array}$ & 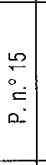 & $\mid \begin{array}{c}m \\
0 \\
c \\
c \\
c\end{array}$ & $\begin{array}{c}m \\
0 \\
\dot{\Sigma} \\
\alpha\end{array}$ & $\begin{array}{l}\bar{c} \\
\frac{1}{c} \\
0\end{array}$ & 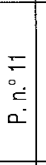 & $\begin{array}{l}0 \\
0 \\
\circ \\
\check{c} \\
0 .\end{array}$ \\
\hline 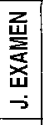 & 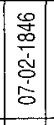 & 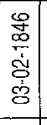 & 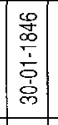 & 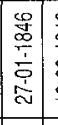 & 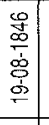 & 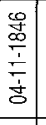 & 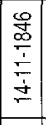 & & 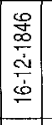 & & 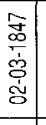 & 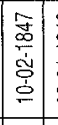 & 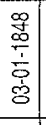 & 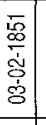 & 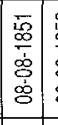 & 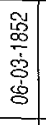 & 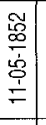 & 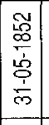 & 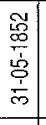 & 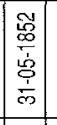 & & 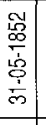 & 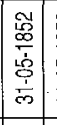 & 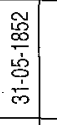 & & 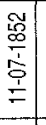 & 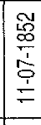 \\
\hline $\begin{array}{l}\text { 哀 } \\
\text { 畜 } \\
\text { 产 }\end{array}$ & 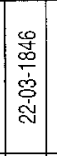 & 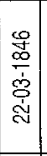 & 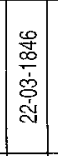 & 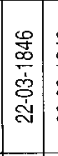 & $\begin{array}{l}0 \\
0 \\
0 \\
0 \\
0 \\
0 \\
0 \\
0 \\
0\end{array}$ & 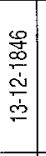 & 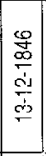 & 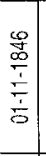 & 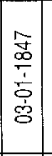 & 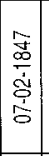 & $\begin{array}{l}\text { 告 } \\
0 \\
0 \\
9 \\
0 \\
0\end{array}$ & 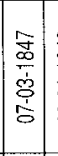 & 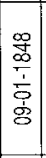 & 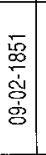 & & 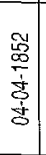 & & 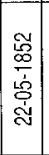 & & & 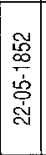 & 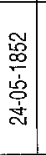 & & & 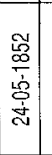 & & \\
\hline 홈 & m & $\stackrel{2}{\sim}$ & $\stackrel{\mathbb{N}}{ }$ & $\stackrel{\mathscr{N}}{\sim}$ & $\bar{m}$ & ల్ల & $\approx$ & 总 & N & & $\stackrel{\infty}{\sim}$ & 앙 & $\overline{\mathrm{s}}$ & 요 & & $\stackrel{\$}{N}$ & $\approx$ & 保 & & 焉 & $\stackrel{4}{\sim}$ & $\stackrel{2}{N}$ & $\mathbb{N}$ & $\mathscr{O}$ & $\bar{\sim}$ & & $\bar{m}$ \\
\hline $\begin{array}{l}\text { 豆 } \\
\text { 少 }\end{array}$ & 요 & 吕 & g্ল & $\bar{m}$ & $=$ & 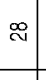 & 寽 & & $\infty$ & $F$ & $\infty$ & 守 & $\cong$ & $\stackrel{\infty}{\sim}$ & 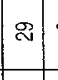 & $\infty$ & $=$ & $F$ & o) & $\bar{v}$ & $\approx$ & 8 & 品 & 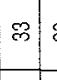 & $\stackrel{\sim}{\sim}$ & $\simeq$ & $\stackrel{\infty}{\stackrel{0}{2}}$ \\
\hline 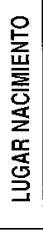 & 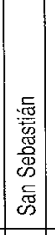 & 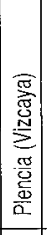 & 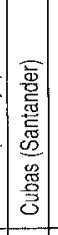 & 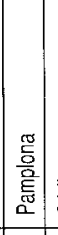 & \begin{tabular}{|l|} 
\\
\\
\end{tabular} & $\begin{array}{l}\text { 읗 } \\
\text { एँ } \\
\end{array}$ & \begin{tabular}{|l|} 
용 \\
잉 \\
\end{tabular} & 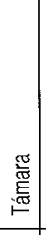 & 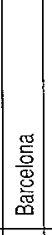 & 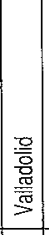 & 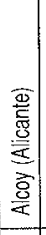 & 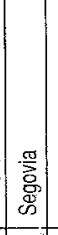 & 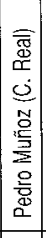 & 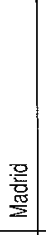 & 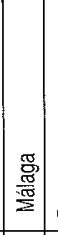 & 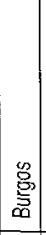 & 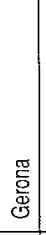 & 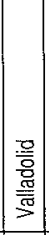 & 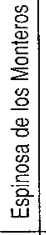 & 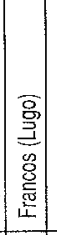 & 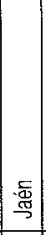 & 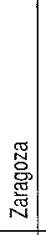 & $\begin{array}{l} \\
\text { 은 } \\
\text { 흘 } \\
2\end{array}$ & 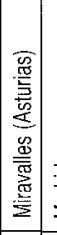 & 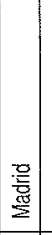 & 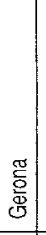 & 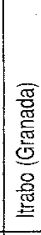 \\
\hline 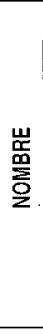 & 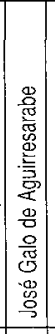 & 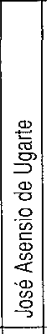 & 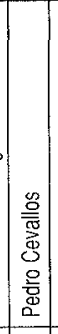 & 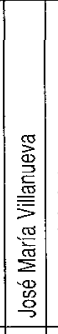 & 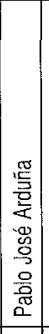 & 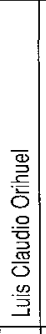 & 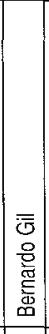 & 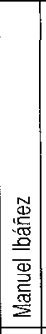 & 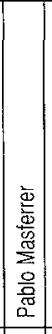 & 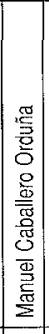 & 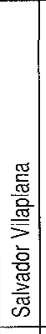 & 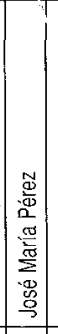 & 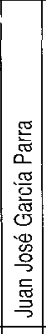 & 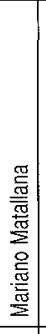 & 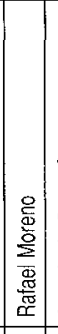 & 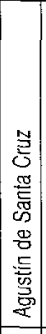 & 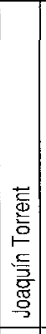 & 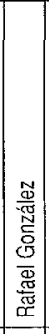 & 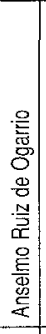 & 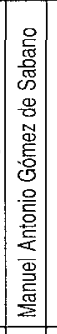 & 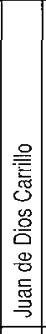 & 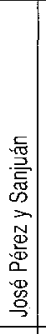 & 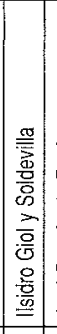 & 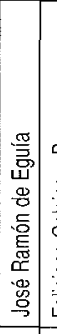 & 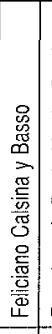 & 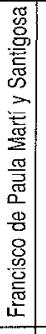 & 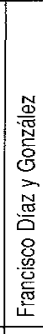 \\
\hline & 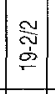 & 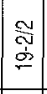 & 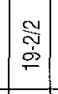 & 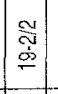 & $\begin{array}{l}\widetilde{N} \\
\sigma \\
\sigma \\
\sigma\end{array}$ & 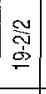 & 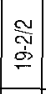 & 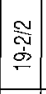 & 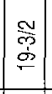 & 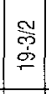 & $\begin{array}{l}\stackrel{N}{\sigma} \\
\stackrel{\gamma}{\sigma} \\
\end{array}$ & 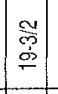 & 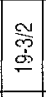 & $\begin{array}{l}\frac{w}{y} \\
\sigma \\
\end{array}$ & 寽 & 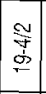 & 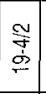 & 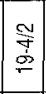 & $\begin{array}{c}\frac{N}{9} \\
\frac{1}{\sigma}\end{array}$ & 誉 & \begin{tabular}{|l}
$\frac{N}{5}$ \\
$\frac{1}{5}$ \\
\end{tabular} & 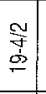 & 学 & 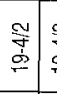 & $\begin{array}{l}\text { 学 } \\
\stackrel{5}{\circ}\end{array}$ & $\stackrel{\text { 等 }}{\stackrel{5}{\sigma}}$ & $\begin{array}{l}\text { 等 } \\
\end{array}$ \\
\hline & $\bar{\sim}$ & $\stackrel{\infty}{\sim}$ & $\frac{O}{\sim}$ & జี & $\overline{\mathrm{N}}$ & สี & సี & $\approx$ & : & $\stackrel{\Xi}{*}$ & J & : & : & ్్ & $\overline{\tilde{N}}$ & న్ & $\stackrel{\mathscr{c}}{\mathrm{N}}$ & $\mathbb{E}$ & $\stackrel{\text { ֻ̆ }}{\mathrm{N}}$ & 总 & 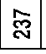 & 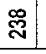 & 总 & 学 & $\overline{\mathrm{D}}$ & $\tilde{\sim}$ & $\tilde{N}$ \\
\hline
\end{tabular}




\begin{tabular}{|c|c|c|c|c|c|c|c|c|c|c|c|c|c|c|c|c|c|c|c|c|c|c|c|c|c|}
\hline 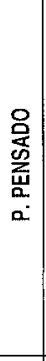 & 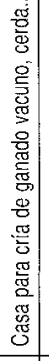 & 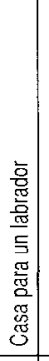 & 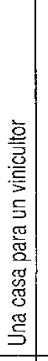 & 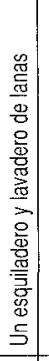 & 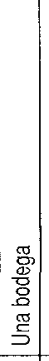 & 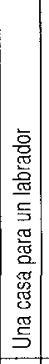 & 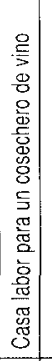 & 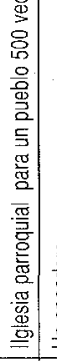 & 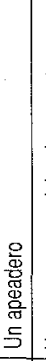 & & 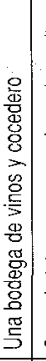 & 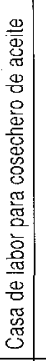 & 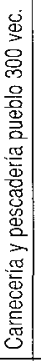 & 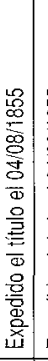 & 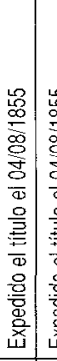 & 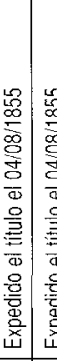 & 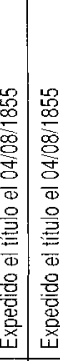 & 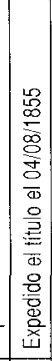 & 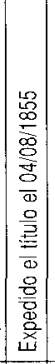 & 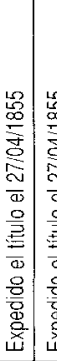 & 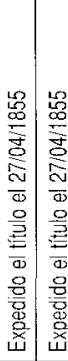 & 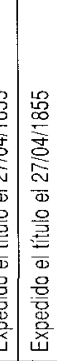 & 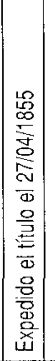 & 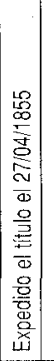 & 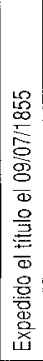 \\
\hline i & & & & & & & & & & & & & & & & & & & & & & & & & \\
\hline 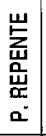 & 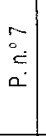 & \begin{tabular}{l|l}
0 & \\
$\circ$ \\
$c$ \\
0 \\
0
\end{tabular} & 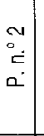 & \begin{tabular}{ll} 
& 0 \\
0 \\
$\doteqdot$ \\
\hdashline \\
0
\end{tabular} & 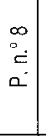 & $\mid \begin{array}{l}\vec{y} \\
\dot{a} \\
\dot{c} \\
\dot{\alpha}\end{array}$ & & & 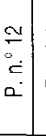 & 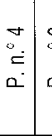 & $\begin{array}{l}\infty \\
0 \\
= \\
0 \\
0 \\
0\end{array}$ & $\begin{array}{l}m \\
= \\
= \\
0 \\
0\end{array}$ & 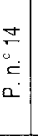 & & & & & & & & & & & & \\
\hline 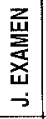 & 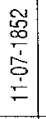 & 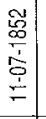 & 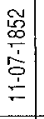 & 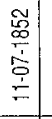 & 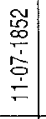 & 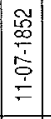 & $\begin{array}{l}\stackrel{\widetilde{\infty}}{0} \\
\stackrel{\infty}{\dot{b}} \\
\stackrel{+}{=} \\
\end{array}$ & 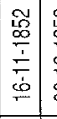 & 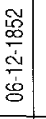 & 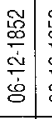 & 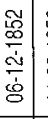 & 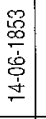 & 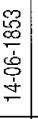 & & & & & & & & & & & & \\
\hline 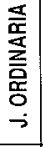 & 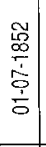 & & & & & & & & & & & 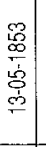 & 然 & 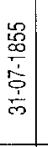 & 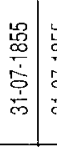 & 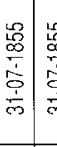 & 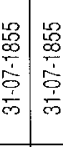 & $\begin{array}{l}\frac{\mathscr{L}}{0} \\
\frac{0}{0} \\
\frac{1}{0} \\
\frac{1}{m}\end{array}$ & 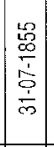 & 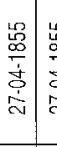 & 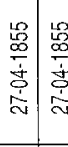 & 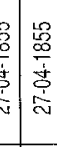 & 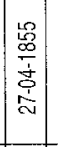 & 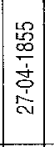 & \\
\hline 옳 & $\bar{N}$ & $\approx$ & ৪) & बi & \pm & $\approx$ & $\infty$ & $\stackrel{m}{m}$ & $\approx$ & 志 & $\stackrel{\mathbb{2}}{\sim}$ & हి & $\stackrel{\infty}{\approx}$ & N & $\approx$ & $\stackrel{1}{2}$ & $\stackrel{ \pm}{ \pm}$ & $\stackrel{ \pm}{*}$ & $\bar{N}$ & স্র & ले & $\stackrel{0}{6}$ & $\mid$ & 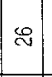 & \\
\hline 总 & $\stackrel{\mathbb{N}}{\sim}$ & $\stackrel{\infty}{\sim}$ & $\stackrel{\infty}{\sim}$ & $\stackrel{\infty}{\sim}$ & 覀 & 愢 & 舀 & 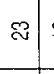 & 으 & $\infty$ & 号 & $\stackrel{m}{-1}$ & $\mathbb{N}$ & $\bar{\sigma}$ & $\bar{y}$ & $\stackrel{\infty}{\sim}$ & F) & - & 罚 & $0:$ & \begin{tabular}{l|l}
$\stackrel{\infty}{\subseteq}$ & 7
\end{tabular} & $\begin{array}{l}f \\
f\end{array}$ & 舀 & 䍐 & g \\
\hline 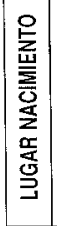 & 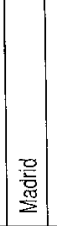 & $\mid \begin{array}{l}\text { 을 } \\
\text { 焉 }\end{array}$ & $\begin{array}{l}\text { 을 } \\
\text { 물 }\end{array}$ & \begin{tabular}{|c|} 
읗 \\
$\frac{\pi}{2}$
\end{tabular} & 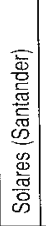 & 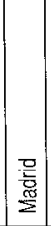 & 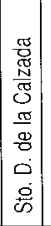 & 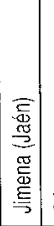 & 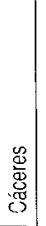 & 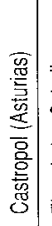 & 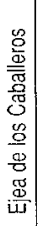 & 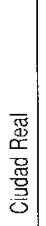 & $\Xi$ & 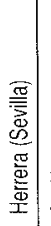 & 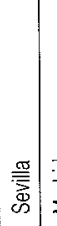 & $\begin{array}{l}\text { 믐 } \\
\text { क्ष }\end{array}$ & 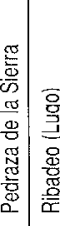 & 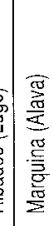 & 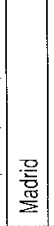 & 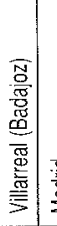 & 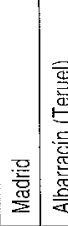 & 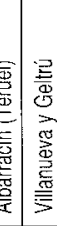 & 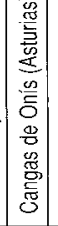 & \begin{tabular}{|l|} 
\\
$\frac{0}{\overline{7}}$ \\
$\frac{\pi}{2}$ \\
$\frac{\pi}{2}$
\end{tabular} & 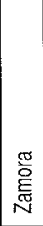 \\
\hline
\end{tabular}

은 


\begin{tabular}{|c|c|c|c|c|c|c|c|c|c|c|c|c|c|c|c|c|c|c|c|c|c|}
\hline $\begin{array}{l}\frac{8}{8} \\
\text { 勇 } \\
\text { 岃 } \\
\alpha^{-}\end{array}$ & 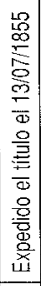 & 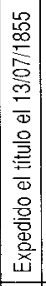 & 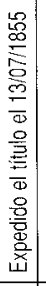 & 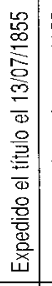 & 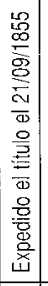 & 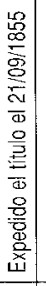 & 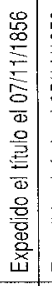 & 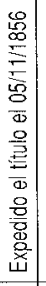 & 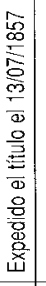 & 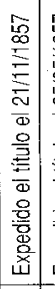 & 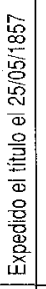 & 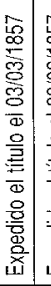 & 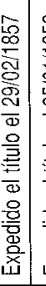 & 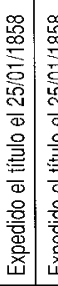 & 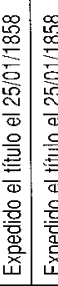 & 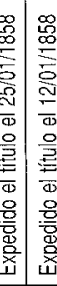 & 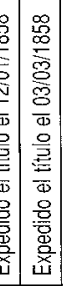 & 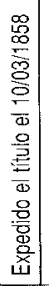 & 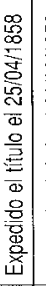 & 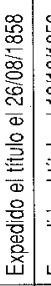 & 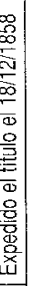 \\
\hline is & & & & & & & & & & & & & & & & & & & & & \\
\hline & & & & & & & & & & & & & & & & & & & & & \\
\hline & & & & & & & & & & & & & & & & & & & & & \\
\hline 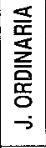 & 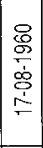 & 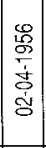 & 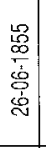 & 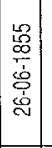 & 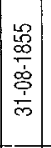 & 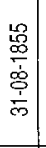 & 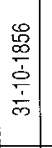 & 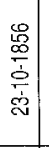 & 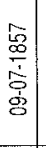 & 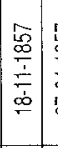 & 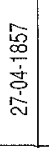 & 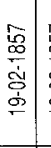 & 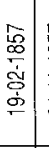 & 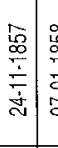 & 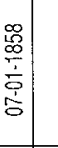 & & 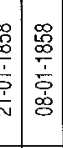 & 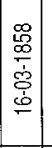 & 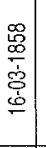 & 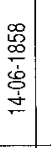 & \\
\hline 喜 & 骂 & $\stackrel{m}{m}$ & $\mathscr{尺}$ & I & ल) & ळ & $\bar{\wedge}$ & $\stackrel{\infty}{\sim}$ & 8 & के & & 品 & $\stackrel{\infty}{\infty}$ & $\bar{\sigma}$ & 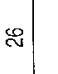 & $\vec{\Delta}$ & $\mathbb{N}$ & $\mathscr{\sim}$ & $\stackrel{2}{\sim}$ & $\stackrel{\mathscr{N}}{ }$ & \\
\hline 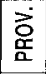 & $\stackrel{\infty}{\sim}$ & 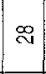 & 10 & 寸 & 守 & 8 & $\bar{m}$ & & $\mathfrak{N}$ & $\stackrel{\infty}{\sim}$ & & ల్ల & - & \pm & $\Sigma$ & $g$ & $g: \forall$ & $\widehat{N}$ & & F & \\
\hline 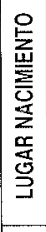 & 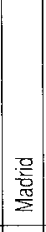 & $\mid \begin{array}{l}\frac{\mathrm{O}}{\mathrm{i}} \\
\frac{\mathrm{N}}{2}\end{array}$ & 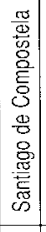 & 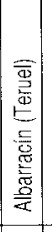 & \begin{tabular}{|l|} 
\\
\\
0
\end{tabular} & 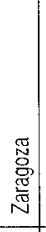 & 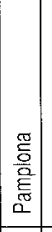 & & 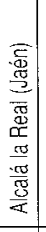 & :응 & 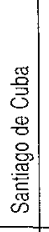 & 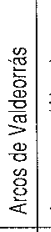 & 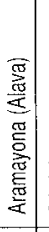 & : & 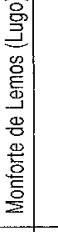 & & 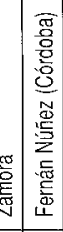 & 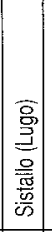 & 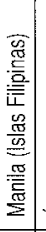 & 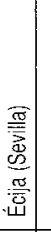 & \\
\hline $\begin{array}{l}\text { 峞 } \\
\text { 产 }\end{array}$ & 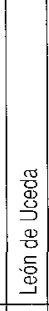 & 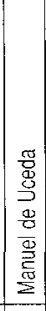 & 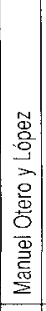 & 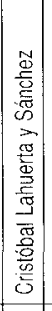 & 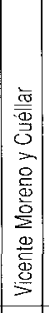 & 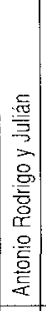 & 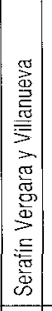 & 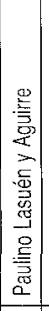 & 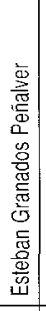 & 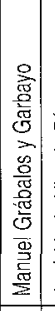 & 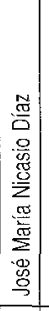 & 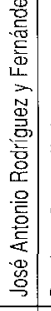 & 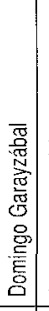 & 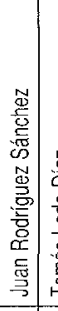 & 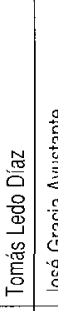 & 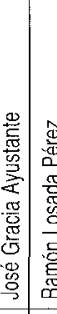 & 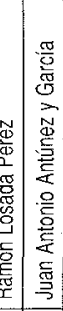 & 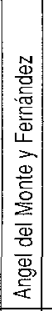 & 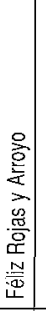 & 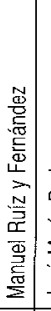 & 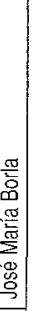 \\
\hline$\Xi$ & 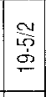 & 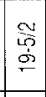 & 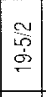 & 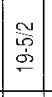 & 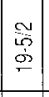 & 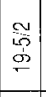 & 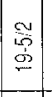 & 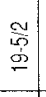 & \begin{tabular}{l} 
N \\
$\stackrel{5}{\sigma}$ \\
\hdashline
\end{tabular} & 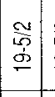 & $\begin{array}{l}\text { 荝 } \\
\stackrel{\leftrightarrow}{\sigma} \\
\end{array}$ & 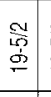 & 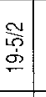 & 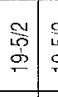 & 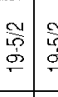 & 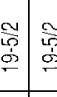 & 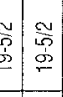 & 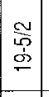 & 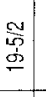 & $\begin{array}{l}\frac{N}{5} \\
\stackrel{5}{\sigma} \\
\stackrel{0}{-}\end{array}$ & 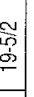 \\
\hline & $\overline{\mathbf{N}}$ & 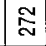 & 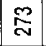 & $\underset{\sim}{\mathbb{N}}$ & $\stackrel{\sim}{\sim}$ & $\stackrel{\cong}{\sim}$ & N & 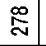 & 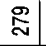 & 总 & $\stackrel{\bar{a}}{\mathrm{~N}}$ & ⿷্ণ & : & 志 & $\stackrel{\mathscr{m}}{\stackrel{\infty}{\sim}}$ & \begin{tabular}{c|c}
$\infty$ & 1 \\
$\stackrel{\infty}{\sim}$ & $\infty$ \\
\end{tabular} & \begin{tabular}{c}
5 \\
\hdashline
\end{tabular} & 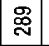 & 品 & $\bar{N}$ & $\mathrm{~N}$ \\
\hline
\end{tabular}


